Article

\title{
From Nanostructural Characterization of Nanoparticles to Performance Assessment of Low Clinker Fiber-Cement Nanohybrids
}

\author{
Styliani Papatzani ${ }^{1,2, *(1)}$ and Kevin Paine ${ }^{2}$ (C) \\ 1 Hellenic Ministry of Culture and Sports, Directorate of Restoration of Medieval \& Post-medieval \\ Monuments, Tzireon 8-10, Athens 11742, Greece \\ 2 BRE Centre for Innovative Construction Materials, University of Bath, Bath BA2 7AY, UK; k.paine@bath.ac.uk \\ * Correspondence: spapatzani@gmail.com
}

Received: 20 April 2019; Accepted: 7 May 2019; Published: 11 May 2019

check for updates

\begin{abstract}
With the current paper three nano-Montmorillonites $(\mathrm{nMt})$ are applied in cement nanohybrids: an organomodified nMt dispersion, $\mathrm{nC2}$; an inorganic $\mathrm{nMt}$ dispersion, $\mathrm{nC}$; and an organomodified powder, nC4. nC4 is fully characterized in this paper (X-ray diffraction, scanning electron microscopy/X-ray energy dispersive spectroscopy and thermal gravimetric analysis/differential thermogravimetry. Consecutively a ternary non pozzolanic combination of fiber-cement nanohybrids (60\% Portland cement (PC) and 40\% limestone (LS)) was investigated in terms of flexural strength, thermal properties, density, porosity, and water impermeability. Flexural strength was improved after day 28 , particularly with the addition of the inorganic nMt dispersion. There was no change in density or enhancement in pozzolanic reactions for the powder nMt. Mercury intrusion porosimetry showed that the pore related parameters were increased. This can be attributed to mixing effects and the presence of fibers. Water impermeability tests yielded ambiguous results. Clearly, novel manufacturing processes of cement nanohybrids must be developed to eliminate mixing issues recorded in this research.
\end{abstract}

Keywords: low PC clinker; Portland limestone ternary fiber-cement nanohybrids; flexural strength; TGA/dTG; XRD; MIP; water impermeability tests

\section{Introduction}

Soil constitutes of clay minerals, which are classified according to their internal structure as 1:1 (one tetrahedral silicate sheet bonded to one octahedral hydroxide sheet) or 2:1 (one octahedral hydroxide sheet sandwiched between two tetrahedral silicate sheets). The latter group consists of illites, Kaolins, smectites, and others. Montmorillonite (MMT) is a dioctahedral smectite (one $\mathrm{SiO}_{2}$ platelet/layer sandwiched between two $\mathrm{Al}_{2} \mathrm{O}_{3}$ platelets/layers). It can be found in pure form or in the form of bentonite, in which $50 \%-80 \%$ MMT is intermixed with chlorite, muscovite, illite, and kaolinite. If bentonite undergoes a purification process with the use of sodium ions, "sodium bentonite" is produced, which practically is pure MMT. Montmorillonite is; therefore, a two-dimensional naturally hydrophilic stack of platelets of nanosized thickness [1]. The lateral dimensions vary from a few nanometers to a few hundreds of micrometers [2].

Given that the European Commission in 2011 has specified that "nanomaterial" means a natural, incidental, or manufactured material containing particles, in an unbound state or as an aggregate or as an agglomerate and where, for $50 \%$ or more of the particles in the number size distribution, one or more external dimensions is in the size range 1-100 $\mathrm{nm}$ [3]. It is only natural that an extensive number of scientists are involved into the separation of the platelets in order to produce individually reactive 
platelets of nanosized thickness, generally termed as "nanoclay." If an organic surface modifier is inserted in the MMT layers to separate them, then an organomodified MMT (OMMT) is produced and is considered to be nano-Montmorillonite $(\mathrm{nMt})$. Then, nanoclays or $\mathrm{nMt}^{\prime} \mathrm{s}$ can be dispersed in ceramic, metallic, biopolymeric, or polymeric matrixes or in water. The preferred manufacturing and fabrication method depends on the purpose of use of the nanoclays or nMt's. Ultrasonic sonication, planetary centrifugal mixing, magnetic dispersion, roll milling, and combinations of them have been investigated. For example, a significant number of papers is published on the effect of the nanoclay dispersion methods on the mechanical behavior of E-glass/epoxy nanocomposites $[4,5]$ or clay-polymer nanocomposites [6-8].

The use of nanoclays is widespread in environmental science; for example, for removal of contaminants in water [9], remediation of contaminated soils [10] or biodegradation of polyolefins [11], in medicine for drug delivery [12], and in other fields. The use of nanoclays in cement science is limited, notwithstanding the size compatibility between the main hydration product of cement, $\mathrm{C}-\mathrm{S}-\mathrm{H}$, which is nanosized [13] and nMt, which is in the same order of the nanocrystalline structure of C-S-H [14]. In fact, most studies investigate the effect of the addition of thermally- and mechanically-treated (calcined at temperatures above $700^{\circ} \mathrm{C}$ ) nanoclays, predominantly kaolinites [15], MMT's or micro-sized OMMT [16], despite the environmental cost due to the calcination process [17]. Others, report results on the use of industrial nMt's (in liquid form purchased from J Nano Technology Co., Ltd.) used as an admixture without providing any characterization of the nanoparticles [14].

In recent years a number of studies are suggesting the replacement of Portland cement by an amount of nanoclays or nMt's in composite cements in an effort to produce "green" cementitious nanohybrids (i.e., nanohybrids that contain minimum amount of Portland cement clinker), which is accountable for almost $8 \%$ of the global manmade $\mathrm{CO}_{2}$ emissions. As summarized in Figure 1, binary cements comprising PC and LS should not contain less than $65 \%$ PC. The same is valid for composite cements containing PC and/or LS/Fly ash/blast furnace slag/pozzolanas/silica fume, according to the Eurocodes [18]. Any other combination beyond these restrictions can potentially incur a series of issues, such as prolonged setting times, reduced compressive strengths, non-homogeneous microstructure.

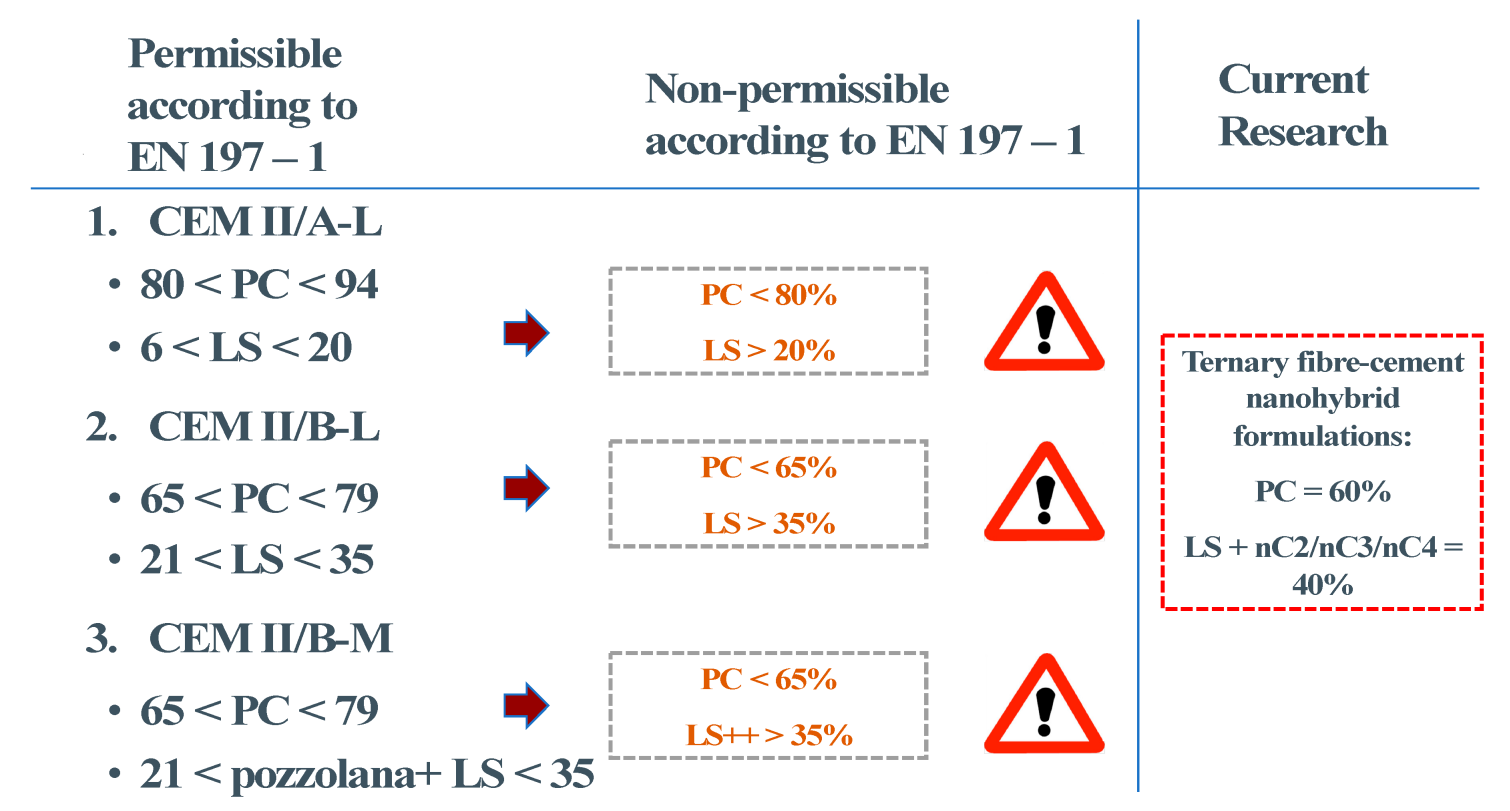

Figure 1. Permissible and non-permissible limits of clinker substitution/SCM (Supplementary Cementitious Materials) addition according to EN197-1 and challenge of current research. (PC stands for Portland cement and LS for limestone) 
One of the key challenges in this paper was to produce fiber-cement nanohybrids with lower PC content than the one allowed by the current design codes (Figure 1) in an effort to design a "greener" formulation. It has been suggested that the direction of the platelets in intercalated or exfoliated nMt's may affect the load path and crack propagation within nanomodified pastes [19]. Moreover, it has been argued that nMt particles may further exfoliate within the hydrating cement matrix, tending to disperse in one direction under stirring [20], rendering them possibly more suitable for flexural than compressive strength enhancement. Adding to this, a recent study on $1 \%$ nanoclay addition to CEMI mortars showed an enhancement in the rate of strength gain for flexure [21] with respect to rate of strength gain for compression. However, although comparison for compression was made at day seven, 28 , and 91 , the comparison for flexure was made between seven and 28 days only and the matrix was binary, containing solely PC and nanoclay. What is important, though, is that nanoclay performed better in flexure, attributing to better adhesion of the specific nanoparticles in the matrix.

As shown in Table 1, the way the nanoparticles are produced affects the properties of the cementitious nanocomposites they will form. In fact, although a significant diversity of manufacturing and fabrication methods of nanoclays and nMt's exist for various applications as discussed earlier, as reviewed in Table 1, for cementitious nanocomposites the most common methods include ultrasonic sonication, ball milling, and electrical mixing. Still, in the reported papers, all formulations are binary $(\mathrm{PC}+\mathrm{nMt})$ except for one [22], hence there is a broad field for the investigation of higher order formulations, containing more than two constituents.

Table 1. Manufacturing and fabrication method of nano-montmorillonites/nanoclays suitable for cement nanocomposites according to literature.

\begin{tabular}{|c|c|c|c|c|}
\hline $\begin{array}{l}\text { Manufacturing and } \\
\text { Fabrication Method }\end{array}$ & Cement Mix & Characterization Technique & Selected Results & Reference \\
\hline Ultrasonic sonication & $\begin{array}{l}\text { Ordinary Portland cement (OPC) type } \\
42.5 \mathrm{R} \text { and commercially available } \\
\text { nano-kaolinite clay (NKC) powder was } \\
\text { added as Portland cement (PC) } \\
\text { replacement at } 0 \%, 1 \%, 3 \% \text {, and } 5 \% \text { by } \\
\text { weight. } \\
\text { The NKC was first dispersed in water } \\
\text { using an ultrasonic dispersion method. }\end{array}$ & $\begin{array}{l}\text { X-ray diffraction (XRD) analysis } \\
\text { and transmission electron } \\
\text { microscopy (TEM) techniques } \\
\text { were carried out on the clay } \\
\text { powder. }\end{array}$ & $\begin{array}{l}\text { The samples with } 5 \% \text { NKC } \\
\text { exhibited the highest } \\
\text { compressive strength, chloride } \\
\text { diffusion resistivity, relative } \\
\text { dynamic modulus of elasticity, } \\
\text { and the most electrical resistivity } \\
\text { after } 125 \text { freeze-thaw cycles. }\end{array}$ & [23] \\
\hline Hobart electric mixer & $\begin{array}{l}\text { OPC is partially substituted by } 1 \%, 2 \% \text {, or } \\
3 \% \text { nanoclay by weight of OPC. The OPC } \\
\text { and nanoclay were first dry mixed for } 5 \\
\text { min in Hobart mixer at a low speed and } \\
\text { then mixed for another } 10 \text { min at high } \\
\text { speed until homogeneity was achieved. } \\
\text { Cloisite } 30 \mathrm{~B} \text { is a natural montmorillonite } \\
\text { modified with a quaternary ammonium } \\
\text { salt, which was supplied by Southern } \\
\text { Clay Products, USA. }\end{array}$ & X-ray diffraction (XRD) analysis. & $\begin{array}{l}\text { The nanoclay behaves not only } \\
\text { as a filler to improve } \\
\text { microstructure, but also as an } \\
\text { activator to promote pozzolanic } \\
\text { reaction. }\end{array}$ & [24] \\
\hline Electric mixer & $\begin{array}{l}\text { OPC mortars where produced by partial } \\
\text { substitution with NMK at } 2 \%, 4 \%, 6 \% \text {, } \\
\text { and } 8 \% \text { by weight of cement. The } \\
\text { nanoclay used in this investigation is } \\
\text { kaolin clay supplied by Middle East } \\
\text { Mining Investments Company (MEMCO), } \\
\text { Cairo, Egypt. The nano-kaolin was } \\
\text { heated for } 2 \mathrm{~h} \text { at } 750{ }^{\circ} \mathrm{C} \text { to give active } \\
\text { amorphous NMK. } \\
\text { The ingredients were homogenized on an } \\
\text { electric mixer to assure complete } \\
\text { homogeneity. }\end{array}$ & TEM imaging of NMK. & $\begin{array}{l}\text { The compressive strength and } \\
\text { the tensile strength of the } \\
\text { cement mortars with NMK were } \\
\text { higher than the reference mortar } \\
\text { at the same water to binder } \\
\text { (w/b) ratio. The enhancement in } \\
\text { tensile strength reached } 49 \% \text {, } \\
\text { whereas the enhancement in } \\
\text { compressive was } 7 \% \text { at } 8 \% \\
\text { NMK. }\end{array}$ & [25] \\
\hline Electric mixer & $\begin{array}{l}\text { A total of } 1 \% \text { or } 2 \% \\
\text { Nano-montmorillonite modified foamed } \\
\text { paste was produced with a high volume } \\
\text { ( } 70 \% \text { ) fly ash binder. The nMt used was } \\
\text { produced by Zhejiang FengHong New } \\
\text { Materials Co., Ltd., which has a purity of } \\
99.5 \% \text { (Technical Grade) } \\
\text { The foaming agents and stabilizing agent } \\
\text { had been dissolved in the water and used } \\
\text { to soak the nMt for } 24 \text { h to facilitate its } \\
\text { dispersion. Solids were mixed first and } \\
\text { then mixed with water. Lastly, with the } \\
\text { water containing nMt and foaming } \\
\text { agents. }\end{array}$ & Not applicable. & $\begin{array}{l}\text { Mix constituting of } 70 \% \mathrm{FA}, 1 \% \\
\text { alpha-olen sulfonate (AOS), } 2 \% \\
\text { alcohol ethoxylate } \\
(\mathrm{AEO}), 0.75 \% \mathrm{Na}_{3} \mathrm{PO}_{4} \text { and } 1 \% \\
\text { nMt) exhibited the lowest } \\
\text { thermal conductivity }(0.071 \mathrm{~W} \\
(\mathrm{m} 1 \mathrm{~K} 1)) \text { and reasonably high } \\
\text { strength ( } 3.23 \mathrm{MPa}) \text { at } 28 \text { days. }\end{array}$ & [22] \\
\hline
\end{tabular}


Table 1. Cont.

\begin{tabular}{|c|c|c|c|c|}
\hline $\begin{array}{l}\text { Manufacturing and } \\
\text { Fabrication Method }\end{array}$ & Cement Mix & Characterization Technique & Selected Results & Reference \\
\hline $\begin{array}{l}\text { Electric mixer and ball } \\
\text { mill }\end{array}$ & $\begin{array}{l}\text { The blended cement paste samples were } \\
\text { prepared by partial replacement of } \\
\text { cement with } 2 \%, 4 \%, 6 \%, 8 \%, 10 \%, 12 \% \text {, } \\
\text { and } 14 \% \text { nano-metakaolin (NMK) by } \\
\text { weight of cement. All pastes were } \\
\text { prepared with the same water to cement } \\
\text { (W/C) ratio } 0.3 \text {. } \\
\text { The ingredients of the blended cement } \\
\text { pastes were homogenized on an electric } \\
\text { mixer to assure complete homogeneity. } \\
\text { The NMK was thermally treated at } 750{ }^{\circ} \mathrm{C} \\
\text { for } 2 \mathrm{~h} \text { to assure complete decomposition } \\
\text { and to get active amorphous } \\
\text { nano-metakaolin (NMK). The ingredients } \\
\text { were homogenized on a roller in a } \\
\text { porcelain ball mill with four balls for } 1 \mathrm{~h} \\
\text { to assure complete homogeneity. }\end{array}$ & $\begin{array}{l}\text { Differential thermal analysis } \\
\text { (DTA) was performed for the } \\
\text { nano-kaolin to specify the } \\
\text { decomposition/calcinations } \\
\text { temperature. } \\
\text { XRD to confirm that the } \\
\text { kaolinite phase transformed into } \\
\text { amorphous phase } \\
\text { TEM imaging confirmed the } \\
\text { thermal activation, capturing } \\
\text { reduction in grain size with } \\
\text { ill-defined edges, which } \\
\text { suggests some amorphous } \\
\text { character and results in } \\
\text { increasing the pozzolanic } \\
\text { reactivity of NMK. }\end{array}$ & $\begin{array}{l}\text { The optimum replacement was } \\
\text { found to be } 10 \% \text { with which an } \\
\text { enhancement of compressive } \\
\text { strength by about } 50 \% \text { and } \\
\text { flexure strength by } 36 \% \text { was } \\
\text { achieved. } \\
\text { Microstructure was also } \\
\text { enhanced. }\end{array}$ & [26] \\
\hline $\begin{array}{l}\text { Distilled water and } \\
\text { stirring for the OMMT, } \\
\text { then electric mixing of } \\
\text { the cementitious } \\
\text { nanocomposites }\end{array}$ & $\begin{array}{l}\text { Ordinary Portland cement type CEM } \\
\text { II/A-LL } 42.5 \mathrm{~N}(\mathrm{OPC} \text { ) and OMMT at } 1 \% \\
\text { cement replacement and at water to solid } \\
\text { ratio (w/s) equal to } 0.27 \text {. } \\
\text { Sodium MMT (cation exchange capacity } \\
\text { (CEC) } 105 \text { meq/ } 100 \mathrm{~g} \text { ), was used for } \\
\text { OMMT synthesis in the laboratory by } \\
\text { applying the ion exchange method. } \\
\text { Quaternary ammonium salt (QAS) } \\
\text { methylbenzyl di-hydrogenated tallow } \\
\text { ammonium chloride (Noramium MB2HT } \\
=640 \mathrm{~g} / \text { mol) was selected as a modifier to } \\
\text { produce three OMT denoted as } 06,08, \\
\text { and } 1 \mathrm{M} \text {, respectively (corresponding to } \\
0.6,0.8 \text { and } 1.0 \text { cation exchange degree). } \\
\text { Each OMMT was mixed with distilled } \\
\text { water and stirred rigorously for one day } \\
\text { at } 20^{\circ} \mathrm{C} \text {, to ensure the formation of } \\
\text { well-dispersed suspension. After stirring } \\
\text { time terminated, the OMMT-water } \\
\text { suspension was mixed with the required } \\
\text { amount of cement. }\end{array}$ & $\begin{array}{l}\text { The pozzolanic activity of the } \\
\text { modified clays was determined } \\
\text { by the Frattini test. }\end{array}$ & $\begin{array}{l}\text { The properties of OMMT } \\
\text { modified cement paste vary } \\
\text { according to the cation exchange } \\
\text { degree of the OMMT. } \\
\text { OMMT of lower cation } \\
\text { exchange degree }(0.6 \mathrm{M}) \text { shows } \\
\text { pozzolanic behaviour after } 14 \\
\text { days, while OMMT of higher } \\
\text { cation exchange degree ( } 0.8 \text { and } \\
1 \mathrm{M}) \text { displays the activity later } \\
\text { only after } 28 \text { days. }\end{array}$ & [27] \\
\hline
\end{tabular}

The work presented in this paper was part of a much broader research project, namely FIBCEM, (Nanotechnology-enhanced Extruded Fibre Reinforced For Cement-based Environmentally Friendly Sandwich Material for Building Applications) supported by the EU, involving industrial and academic partners throughout Europe, to investigate nanotechnologically enhanced cements. A number of studies have been conducted and published by the authors on ternary, quaternary, or quinary pastes, which did not include fibers or superplasticizers [28-32]. Of all nanoparticles employed in these studies, the nMt's, which are promising materials for a number of reasons, including the fact that they are naturally occurring, abundant, and cost effective, provided ambiguous results. It was found that their addition at significant concentrations can, indeed, cause a reduction in compressive strength of samples and this was attributed to a number of issues; primarily the modifier and dispersion agent used and the nanostructure of each dispersion itself $[19,33]$, the quantity of nMt addition, and the absence of superplasticizer [1,28]. In summary, results suggest that in ternary (Portland limestone nanocomposites) [32] and quaternary combinations [1] $1 \%$ of nMt addition by total weight of the binder is optimal and can offer strength improvements in pastes.

Although a number of papers have been reported on the flexural performance of binary nanosilica [34], nanotube [35], or nanoclay [36] enhanced cements, no research has been presented in ternary blends reinforced with fibers. It is acknowledged that nMt nanoparticles can improve flexural strength and assign damping properties [37] to pastes they will be added to [19]. Moreover, as stated above, nMt particles may further exfoliate within the hydrating cement matrix, dispersing in one direction under stirring [20], rendering them possibly more suitable for flexural than compressive strength enhancement. For this, a new research program was implemented in order to assess the potentials of $\mathrm{nMt}$ in ternary fiber-cementitious nanohybrids, when tested in flexure. For the first time, the effect of differently manufactured $\mathrm{nMt}^{\prime} \mathrm{s}$, namely; one organically modified dispersion $(\mathrm{nC} 2)$, 
one inorganic dispersion (nC3), and one organically modified nano-montmorillonite in powder form, industrial product, (nC4) was evaluated. In the present study, the optimal nMt content, (1\% addition of $\mathrm{nC} 2$ or $\mathrm{nC} 3$ or $\mathrm{nC} 4$ by total mass of binder) as defined by previous studies, was investigated. Furthermore, Polyvinylalcohol (PVA) fibers were used as a low-cost type of fiber to provide resistance to cracking and to crack propagation [38]. To the best knowledge of the authors, such an extensive investigation of the nMt properties and the properties of the low-PC fiber reinforced nanohybrids has never been presented before.

\section{Materials and Methods}

\subsection{Materials and Nanomaterials}

The materials used were:

- Portland limestone cement CEMII/A-L42.5, with a limestone content of $14 \%$, conforming to EN 197-1. The supplier gave the following clinker composition: $70 \% \mathrm{C}_{3} \mathrm{~S}, 4 \% \mathrm{C}_{2} \mathrm{~S}, 9 \% \mathrm{C}_{3} \mathrm{~A}, 12 \%$ $\mathrm{C}_{4} \mathrm{AF}$. CEM II/A-L42.5. In mix proportioning the Portland cement (PC) content ( $86 \%$ by mass) was considered separately from the limestone (LS) content (14\% by mass)

- Limestone (additional LS), conforming to EN 197-1. The total LS content of each paste was the sum of that contained in the Portland limestone cement and this additional LS.

- Fly ash (FA), conforming to EN 450 . The oxide composition provided by the material data sheet was: $53.5 \% \mathrm{SiO}_{2}, 34.3 \% \mathrm{Al}_{2} \mathrm{O}_{3}, 3,6 \% \mathrm{Fe}_{2} \mathrm{O}_{3}, 4.4 \% \mathrm{CaO}$.

- Organomodified nano-montmorillonite (nMt), $\mathrm{nC2}$ dispersed in water with the help of an alkyl aryl sulfonate surfactant, containing about $15 \%$ by mass of nMt particles.

- Inorganic nano-montmorillonite (nMt), $\mathrm{nC} 3$ dispersed in water with the help of sodium tripolyphosphate, containing about $15 \%$ by mass of $\mathrm{nMt}$ particles.

- Organomodified nano-montmorillonite (nMt), nC4, an industrial product by Sigma-Aldrich, non-dispersed-in powder form. It consists of Montmorillonite K-10 (70-75 wt\%) surface modified with $25-30 \mathrm{wt} \%$ methyl dihydroxyethyl hydrogenated tallow ammonium * Nanomer ${ }^{\circledR}$ I.34 MN. The supplier's data sheet gives the following additional information: $6.5<\mathrm{pH}<7.0$ and density $=1.7 \mathrm{~g} / \mathrm{cm}^{3}$.

- $\quad$ PVA fibers, kuralon $\mathrm{H}-1,4 \mathrm{~mm}$, added at $2 \%$ by weight.

- Superplasticizer viscocrete $20 \mathrm{HE}$, denoted as SP.

\subsection{Methods}

\subsubsection{Formulation of Fiber-Cement Nanohybrids}

To assess this hypothesis of the better flexural performance and to investigate the possibility of creating lower Portland cement (i.e., carbon footprint) formulations, in the present paper a ternary formulation comprising a non-pozzolanic reference paste containing $60 \%$ PC, $40 \%$ LS, 3\% PVA fibers and $2 \%$ superplasticizer, denoted as F.PC60LS40PVA3SP2 (F is for flexure),

The general formula of the matrix of the ternary cementitious nanohybrids was:

$$
\mathrm{PC}(60)+\mathrm{LS}(40-x)+\mathrm{PVA}(3)+\mathrm{SP}(2)
$$

where $x=\%$ of nMt solids and water to solids (W/S) ratio at 0.3 .

The PC content and the water to solids (W/S) ratio was kept constant and the content of $\mathrm{nMt}$ solids was deducted from the LS content. This was done in order to keep the $\mathrm{Ca}(\mathrm{OH})_{2}$ production during PC hydration comparable in all pastes, so as to detect possible pozzolanic reactivity of the nanoparticles in composite cement formulations, as shown in Table 2. 
Table 2. Composition of ternary fiber cement nanohybrids—-proportions \% by total mass of solids.

\begin{tabular}{lcccccc}
\hline \multicolumn{1}{c}{ Sample } & PC (\%) & LS (\%) & nMt (\%solids) & SP (\%) & PVA fibres (\%) & W/S \\
\hline F.PC60LS40PVA3SP2+0\%nC & 60 & 40 & 0 & 2 & 3 & 0.3 \\
F.PC60LS39PVA3SP2+1\%nC2 & 60 & 39 & 1 & 2 & 3 & 0.3 \\
F.PC60LS39PVA3SP2+1\%nC3 & 60 & 39 & 1 & 2 & 3 & 0.3 \\
F.PC60LS39PVA3SP2+1\%nC4 & 60 & 39 & 1 & 2 & 3 & 0.3 \\
\hline
\end{tabular}

Where, PC stands for Portland cement, LS for limestone, nMt for nanomontmorillonite, SP for superplasticizer, PVA for Polyvinyl alcohol and W/S for water to solids ratio.

The mixing procedure was standardized as in the case of research on nanosilica particles presented by the authors [31]. In specific:

- Dry mixing of all powder components was firstly carried out with a spatula by hand. For the powder $\mathrm{nMt}$, mixing was carried out together with PC and LS.

- For formulations containing $\mathrm{nMt}$ in dispersion, the $\mathrm{nC} 2$ or $\mathrm{nC} 3$ dispersion was poured in a separate container together with water, stirred with the use of a magnetic stir bar for $1 \mathrm{~min}$, and then added to the mixed powders.

- The PVA fibers were added last after they had been manually further separated.

- With the addition of water (and $\mathrm{nC} / \mathrm{nC} 3$ where applicable), the paste was mixed employing a dual shaft mixer at $1150 \mathrm{rpm}$ for a duration of up to four min.

\subsubsection{Analytical Testing}

\section{Characterization of $\mathrm{nMt}$}

The characterization of the powder nC4 followed the methodology presented in literature [19]; nc4 was, therefore, characterized in terms of basal spacing via X-ray diffraction (XRD), in terms of shape, size, and basal spacing via transmission electron microscopy (TEM) and elemental composition via scanning electron microscopy/ X-ray energy dispersive spectroscopy (SEM/EDX). The thermal properties of $\mathrm{nC} 4$ were examined via thermal gravimetric analyses (TGA). In greater detail:

X-ray Diffraction: XRD measurements were performed using a D8 ADVANCE X-ray diffractometer with $\mathrm{CuK} \alpha$ radiation. Spectra were obtained in the range $4^{\circ}<2 \theta<20^{\circ}$ at an angular step-size of $0.016^{\circ} 2 \theta$. The state and extent of dispersion-exfoliation of the NMt can be examined by XRD and TEM analysis with monitoring changes in basal spacing [19].

Transmission Electron Microscopy (TEM): Suspension of $10 \mathrm{ng} / \mathrm{mL}$ was prepared using $\mathrm{nC} 4$ and distilled water. Small drops of the diluted solutions were then deposited on copper mesh grids coated with a thin carbon film. Grids were dried at $25^{\circ} \mathrm{C}$ prior to the insertion in the instrument. Samples were examined at a voltage of $120 \mathrm{kV}$ with a GATAN Jeol JEM $1200 \mathrm{mkII}$. Images were recorded on a Gatan Dual View camera.

As explained in [19], when a polycrystalline structure, with randomly oriented grains, forming rings is detected, having the camera constant known, the calculation of the lattice spacing is allowed according to the following adapted formula [39]:

$$
\frac{\mathrm{r}}{2 \mathrm{~L}}=\frac{\lambda}{d} \rightarrow d=\frac{2 \lambda \mathrm{L}}{\mathrm{r}}
$$

where $L$ : the camera length and $\lambda$ : the electron wavelength, which are independent of the specimen and constant for the TEM instrument and $d=d$-value and $r=$ distance from the diffraction center. Since $d$ is inversely proportional to $r$, the largest $d$ value is obtained by the innermost ring. For the specific TEM diffraction analysis, $\lambda L=1$. These results can be compared with $d$ value measured by XRD. The only variable measured with the help of the TEM software was $r$, manually taken to be equal to the distance between the center of the diffraction and the center of each individual ring. As an effect, greater error is expected when comparing TEM and XRD $d$-value measurements. 
Scanning electron microscopy/X-ray energy dispersive spectroscopy (SEM/EDX): For SEM/EDX elemental composition analyses $\mathrm{nC} 4$ was placed uncoated on a sheet of molybdenum, an element absent from the LnS dispersions for unbiased elemental analyses. A matrix of $5 \times 5$ spectra was acquired and the median of the elemental composition was presented. The $\mathrm{Si} / \mathrm{Al}$ ratio was also calculated.

Thermal gravimetric analyses (TGA) and derivative thermogravimetry (dTG) were carried out using a Setaram TGA92 instrument. Approximately $20 \mathrm{mg}$ of $\mathrm{nC} 4$ were placed in an alumina crucible and heated at a rate of $10{ }^{\circ} \mathrm{C} / \mathrm{min}$ from 20 to $1000{ }^{\circ} \mathrm{C}$ under $100 \mathrm{~mL} / \mathrm{min}$ flow of inert nitrogen gas. The differential thermogravimetric curve (DTG) was derived by the TG curve. The first derivative curve was produced for the various samples tested and was used for comparisons instead of the mass loss curve, as it yields sharp distinctive peaks.

Characterization of fiber-cement nanohybrids

Flexural (three-point bending) strength tests were carried out in accordance with BS EN 12467. Mean strength values of three specimens were calculated, as well as standard deviation at day $7,28,56$, and 90.

For the paste characterization, arrest of hydration was performed following two different methodologies: oven drying and solvent exchange, as described by Calabria-Holley et al. [40]. For TGA/dTG, the oven drying technique was adopted. For the MIP investigation, solvent exchange was the technique employed for the arrest of hydration. Isopropanol was selected as the most appropriate solvent according to literature [41,42].

Thermogravimetric analysis (TGA) and derivative thermogravimetry (dTG) were carried out using Setaram TGA92. Each powder sample was placed in an alumina crucible and heated at a rate of $10^{\circ} \mathrm{C} / \mathrm{min}$ from 20 to $1000^{\circ} \mathrm{C}$ in nitrogen atmosphere, as explained above for the characterization of nC4 at day 28,56 , and 90.

X-ray diffraction (XRD) measurements were performed using a D8 ADVANCE $x$-ray diffractometer with $\mathrm{CuK} \alpha$ radiation controlled by a Dell PC. Spectra were obtained in the range $4^{\circ}<2 \theta<60^{\circ}$. Analysis of peaks and $d$-spacing [according to Bragg's law $(\mathrm{n} \lambda=2 \mathrm{~d} \sin \theta)$ was carried out using EVA software, at day 28].

For the late age relative density measurements, BS EN 12390-7:2009 [18] was selected as a basis and the exact procedure followed is covered in literature [31]. Mean density values of three specimens were calculated, as well as standard deviation.

Water impermeability test was modified to account for the much smaller specimen used in this research (slabs $120 \times 40 \mathrm{~mm}$ and $10 \mathrm{~mm}$ thickness) and were carried out in accordance with BS EN 492:2012 at day 7, 28, and 56. A transparent tube of $250 \mathrm{~mm}$ length was used as water column with an internal bore of $29 \mathrm{~mm}$ diameter. A control water column was also adopted to ensure zero water evaporation in the laboratory testing environment.

Mercury intrusion porosimetry (MIP) was executed with an Autopore III-Model unit 9420 supplied by Micromeritics, Hexton, Herts, UK. Stems of $3 \mathrm{~mL}$ capacity were filled with solids of the arrested hydration paste and tested at day 28 .

\section{Results and Discussion}

\subsection{Characterization of $n M t$ Powder (nC4)}

A thorough methodology on the characterization of organomodified and inorganic nano-montmorillonite dispersions that are suitable as supplementary cementitious materials in cement nanohybrids was presented by the authors [19]. It was postulated that the anionic surfactant used in nC2 mostly kept the platelets apart, notwithstanding scarce areas of re-agglomeration. On the contrary, dispersion $\mathrm{nC} 3$ was fully exfoliated. The elemental composition of $\mathrm{nC} 2$ and $\mathrm{nC} 3$ was also given in the related graph, as well as the $\mathrm{Si} / \mathrm{Al}$ ratio as a measure of comparison between dispersions $\mathrm{nC} 2$ and $\mathrm{nC} 3$ and the powder $\mathrm{nC} 4$. Lastly, the thermal properties of $\mathrm{nC} 4$ were investigated in comparison with $\mathrm{nC} 2$ and $\mathrm{nC} 3$. 
The XRD analysis of nC4 yielded a basal spacing ( $d$-value) of $1.8 \mathrm{~nm}$ (Figure 2$)$, which is more expected in unmodified $\mathrm{nMt}$ [43]. The reflection at $4.892^{\circ} 2 \theta$ corresponded to the 001 plane for this $\mathrm{nMt}$ and, as explained in literature [19], the intercalated platelets, being periodically stacked, were traceable by the XRD, whereas the exfoliated platelets, being fully disordered, remained XRD silent [44].

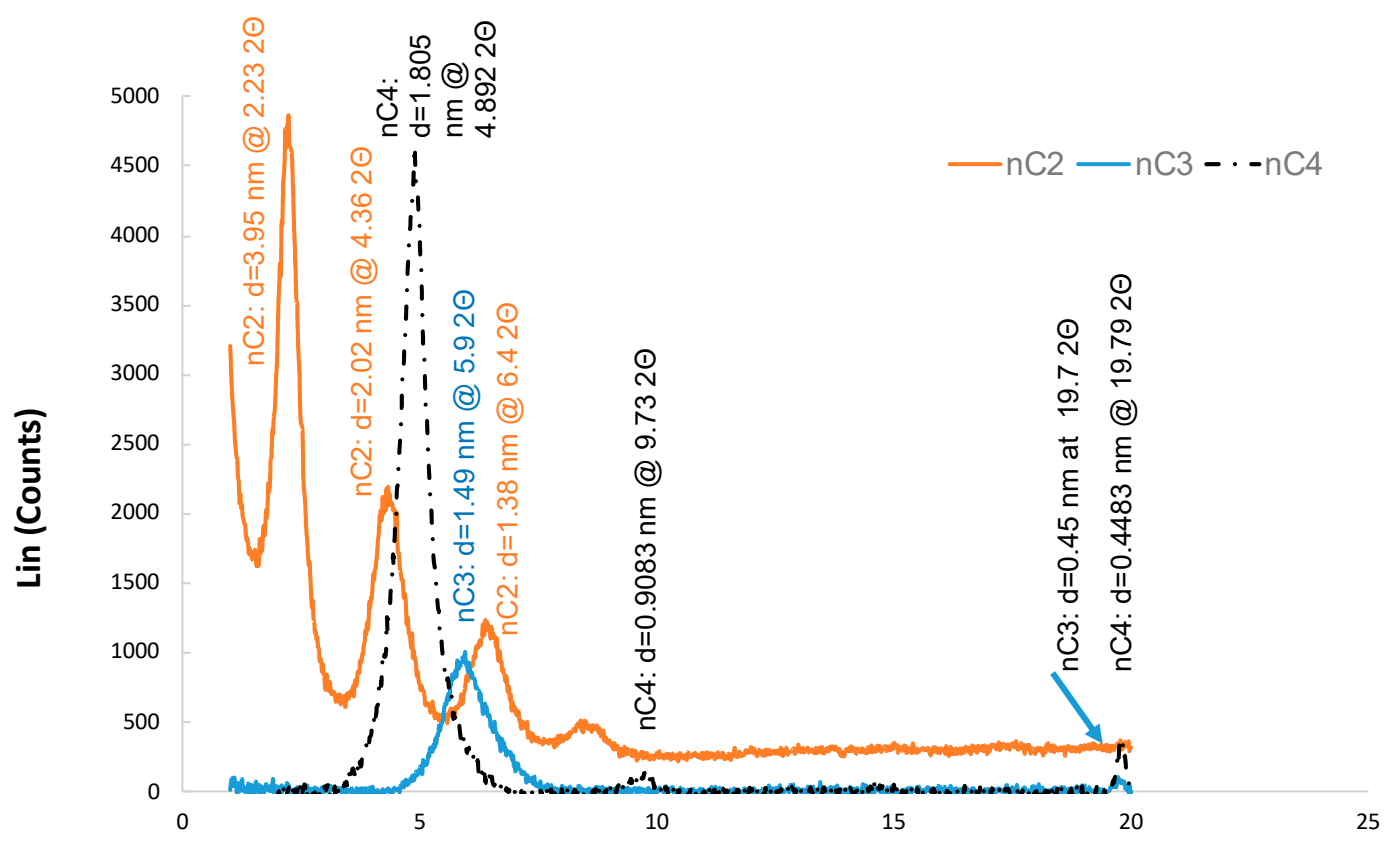

20 Angle

Figure 2. Comparison of the X-Ray diffraction pattern of the organomodified montmorillonite (MMT) dispersion (nC2), inorganic MMT dispersion (nC3) [19], and organomodified MMT powder (nC4).

Although $\mathrm{nC} 4$ was expected to bear resemblance to $\mathrm{nC} 2$, both being organomodified, as shown in Figure 2, the powder OMMT, nC4, in fact, bears greater resemblance to the inorganic dispersion nC3. With respect to the $\mathrm{XRD}$ analysis of $\mathrm{nC} 2$, the reflection at $2.23^{\circ} 2 \theta$ corresponds to the 001 plane. The reflection at $4.36^{\circ} 2 \theta$ corresponds to the 002 plane, while the reflection at $6.4^{\circ} 2 \theta$ corresponds to the 003 plane. Higher order reflections such as 002 and 003, are typical of regular stacking of the modifier chains in the interlayer space [19]. However, the width at medium height of the peak corresponding to the 001 lane provides an estimate of the level of crystallinity of the nMT; therefore, the production process for $\mathrm{nC} 4$ produced less crystalline structures [45].

Lastly the typical montmorillonite reflection at $19.7^{\circ} 2 \theta$, which can act as a measure for the level of exfoliation, was non-existent for $\mathrm{nC} 2$, marginally traceable for $\mathrm{nC} 3$ (which is expected since $\mathrm{nC} 3$ is inorganic), and slightly more traceable for $\mathrm{nC} 4$ (which was not expected since it was organomodified). Therefore, nC2 seemed to have both intercalated (presence of higher order reflection, which are typical of regular stackings) and exfoliated (disappearance of peak at $19.7^{\circ} 2 \theta$ ) platelets, whereas nC3 seemed to be the better exfoliated of all three samples by XRD [19]. The condition of the nanostructure of the $\mathrm{nMt}$ 's is expected to affect the mechanical, chemical, and thermal performance of the samples the $\mathrm{nMt}^{\prime} \mathrm{s}$ will be added to significantly according to previous studies [19,32,46]

TEM micrographs showed good intercalation and possible exfoliation of nC4. Soft edges can be observed in Figure 3A,B. Moreover, nC4 agglomerated less than nC2 or nC3 [19] in water dispersion and showed significant differences in terms of particle shape and size, with platelets reaching the size of $300 \mathrm{~nm}$. 

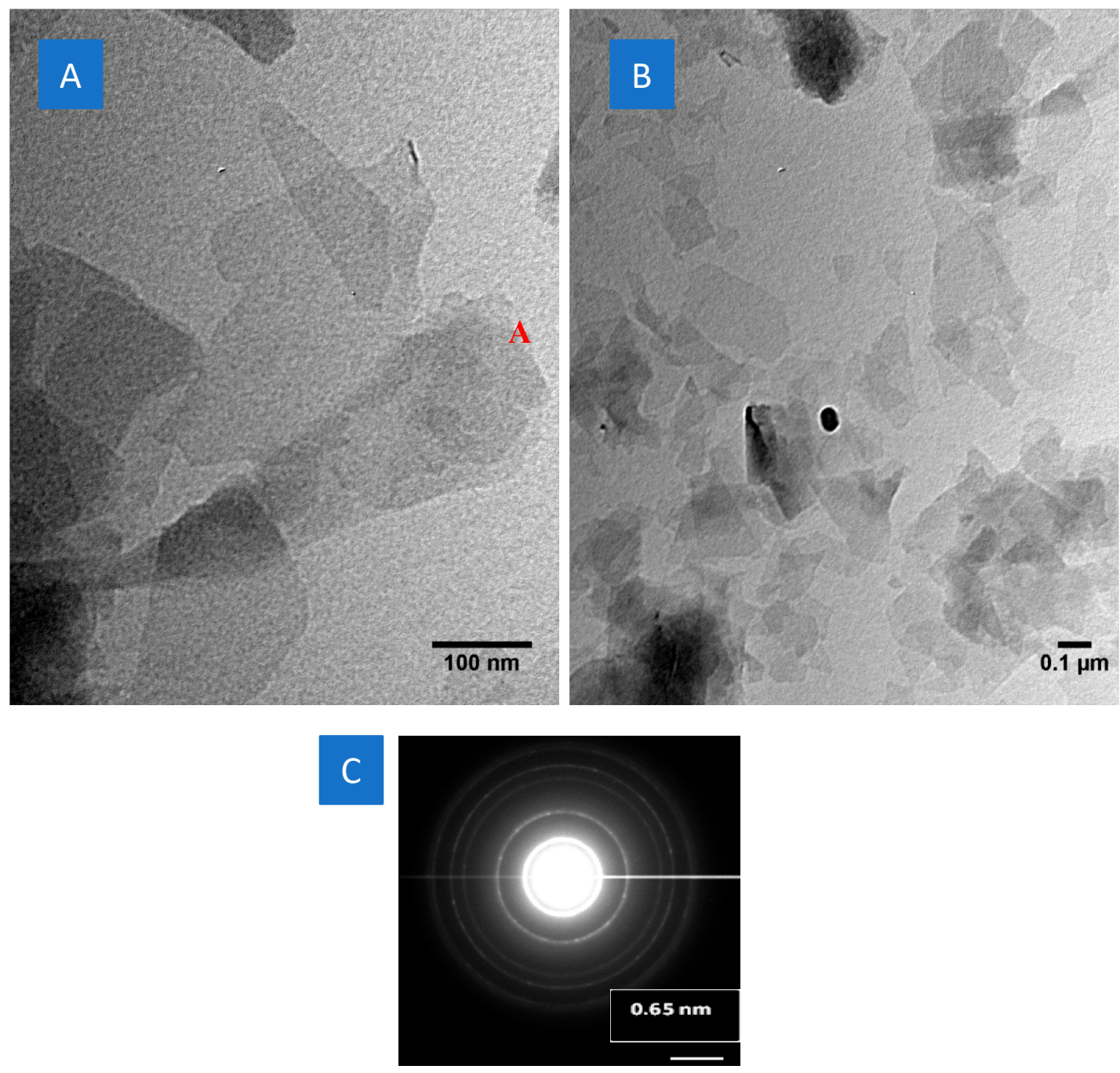

Figure 3. Transmission Electron Microscopy (TEM) micrograph of nC4 at (A) 150,000 times magnification, (B) 50,000 times magnification and, (C) TEM-diffraction pattern of nC4.

The diffraction analysis was carried out according to Equation (2) for the various $d$-values. The $d$-values obtained for the diffraction pattern of nC4 (Figure 3B) were: $d_{1}=2 \times 1 / 0.96=2.08 \mathrm{~nm}, d_{2}$ $=2 \times 1 / 1.83=1.09 \mathrm{~nm}, d_{3}=2 \times 1 / 2.63=0.76 \mathrm{~nm}$, and $d_{4}=2 \times 1 / 3.17=0.63 \mathrm{~nm}$.

It is known that the study of diffraction patterns via TEM can clarify the extent of dispersion or exfoliation of the $\mathrm{nMt}$ [19]. These values clearly indicate that some platelets were intercalated and some exfoliated. The different $d$-spacing $(1.8 \mathrm{~nm})$ given by analysis XRD can be attributed to the fact that diffraction analysis is carried out on a single crystal, whereas XRD in the bulk of the powdered sample. Moreover, a greater error is expected on the TEM results, inherent to the technique adopted to extract the $r$ parameter in Equation (2).

TEM micrographs and diffraction patterns and analyses for $\mathrm{nC} 2$ and $\mathrm{nC} 3$ can be found in literature [19].

TEM imaging and diffraction analysis of $\mathrm{nC} 4$ was followed by SEM/EDS analysis. A matrix of $5 \times 5$ randomly-selected spectra was collected (Table 3). The elemental composition of nC4 (Figure 4) showed that $\mathrm{nC} 4$ contained lower quantities of $\mathrm{C}, \mathrm{Si}$, and $\mathrm{Al}$ compared to the dispersed OMMT, nC2 and higher quantities of $\mathrm{Fe}$ and $\mathrm{O}$. Furthermore, it was comprised of fewer elements and no Na was traced; therefore, $\mathrm{nC} 4$ is not a sodium-MMT originally. The Si/Al ratio of $\mathrm{nC} 4$ was found to be between 3.31 and 3.67 , with a median of 3.48 and a standard deviation of 0.10 . 
Table 3. Scanning electron microscopy/ X-ray energy dispersive spectroscopy (SEM/EDX) counts summary (\% atomic) of $\mathrm{nC} 4$.

\begin{tabular}{|c|c|c|c|c|c|c|}
\hline \multicolumn{7}{|c|}{ Initially Undispersed nC-All Results in Atomic \% Normalized by $100 \%$} \\
\hline Spectrum & $\mathrm{C}$ & $\mathbf{O}$ & Mg & Al & $\mathrm{Si}$ & $\mathrm{Fe}$ \\
\hline$(1,1)$ & 38.63 & 49.13 & 0.55 & 3.29 & 8.01 & 0.40 \\
\hline$(2,1)$ & 39.31 & 45.63 & 0.62 & 3.94 & 9.95 & 0.54 \\
\hline$(3,1)$ & 37.94 & 48.55 & 0.60 & 3.70 & 8.74 & 0.47 \\
\hline$(4,1)$ & 39.87 & 48.95 & 0.47 & 2.86 & 7.40 & 0.44 \\
\hline$(5,1)$ & 38.78 & 47.83 & 0.55 & 3.54 & 8.83 & 0.47 \\
\hline Total mean & 41.01 & 45.56 & 0.51 & 3.37 & 8.30 & 1.25 \\
\hline Standard Deviation & 2.95 & 2.95 & 0.08 & 0.52 & 1.47 & 0.99 \\
\hline
\end{tabular}

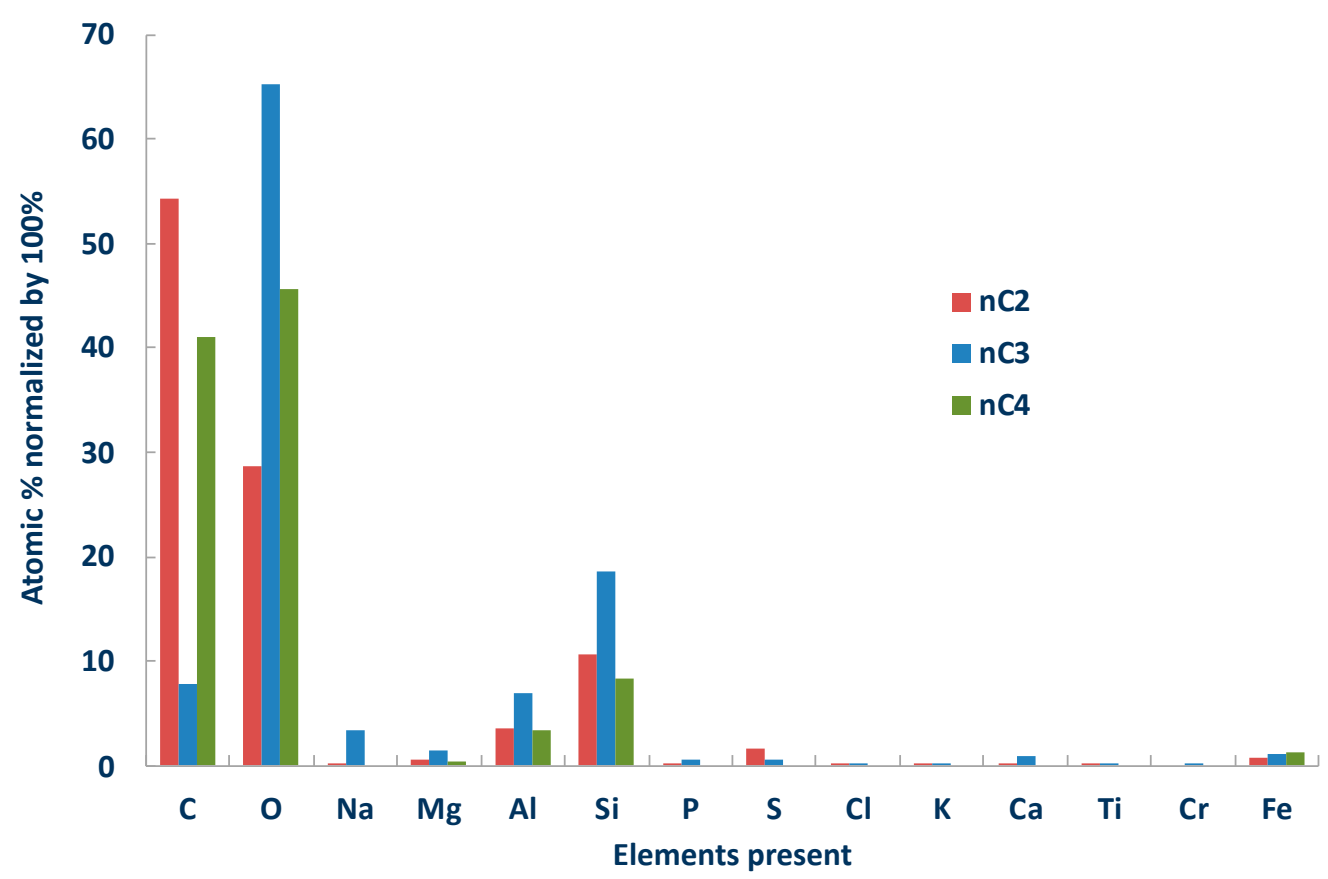

Figure 4. Comparison of the elemental composition of the organomodified nanomontmorillonite (MMT) dispersion (nC2), inorganic MMT dispersion (nC3) [19], and organomodified MMT powder (nC4).

The comparative graphs of the elemental composition and the Si/Al ratios of the organomodified MMT dispersion (nC2), the inorganic MMT dispersion (nC3), and the organomodified MMT powder (nC4) are presented in Figure 5. Values for nC2 and nC3 were found in literature [19]. In summary, the two figures allow for the following conclusions to be drawn:

- $\mathrm{nC2}$ compared to $\mathrm{nC4}$ has higher potential to form additional C-S-H, due to the higher quantities of silica and limited exfoliation. At the same time, the greater amount of carbon present is expected to cause reduction in compressive strengths [19].

- The inorganic nMt, nC3, exhibited the highest net amounts of Si and Al, essential for C-S-H and $\mathrm{C}-\mathrm{Al}-\mathrm{H}$.

- $\quad$ Traces of $\mathrm{Na}$ were found in the $\mathrm{nC} 2$ dispersion, because an anionic surfactant containing $\mathrm{Na}$ was used.

- $\quad$ The pronounced presence of $\mathrm{Na}$ in $\mathrm{nC} 3$ proves that $\mathrm{nC} 3$ was formed by a natural sodium-MMT, whereas the absence of $\mathrm{Na}$ in sample nC4 implies that nC4 was not a sodium-MMT originally.

- The Ca content in nC3 could potentially take part in the C-S-H forming hydration reactions or acting as a seeding agent [13].

- Compared to nC2, the commercially available nC4 was better exfoliated, but showed marginally greater variation in $\mathrm{Si} / \mathrm{Al}$ and more polycrystalline phases. 


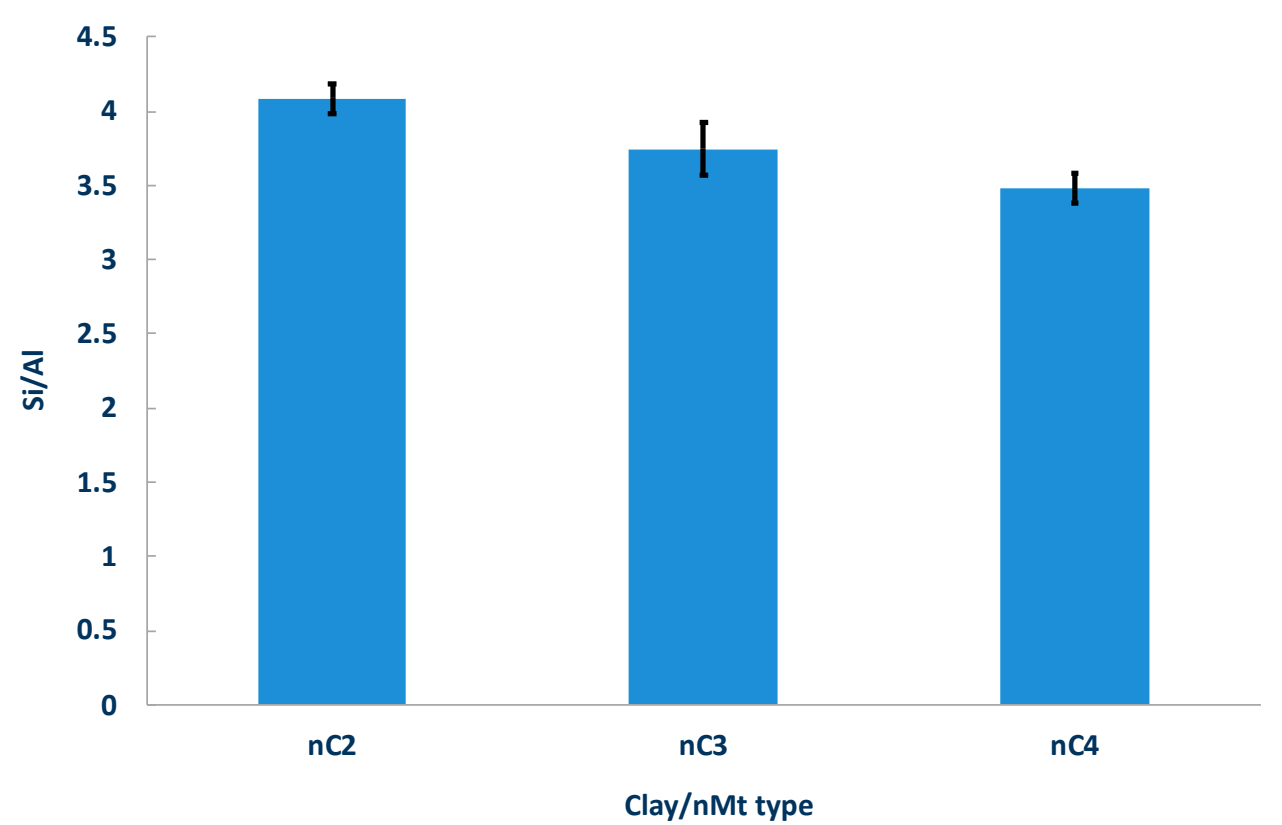

Figure 5. Comparison of the $\mathrm{Si} / \mathrm{Al}$ ratios of the organomodified nanomontmorillonite (MMT) dispersion (nC2), the inorganic MMT dispersion (nC3) [19], and organomodified MMT powder (nC4).

TG analyses of the organomodified MMT dispersion (nC2), inorganic MMT dispersion (nC3), and organomodified MMT powder (nC4).

Thermal analysis of organomodified nMt's is more complex because the modifiers used change the physical, chemical, and, consequently, the thermal characteristics of the nMt's.

Apart from loss of free water, four regions of mass loss of organomodified nMt powders are identified in literature [19]:

- Up to $200{ }^{\circ} \mathrm{C}$, the mass loss is associated with adsorbed interlayer water. Therefore, in the case of the inorganic MMT, a significant mass loss is observed.

- Between 200 and $500{ }^{\circ} \mathrm{C}$ the mass loss is associated with the decomposition of organic elements (modifiers and surfactants) attached to the MMT platelets usually exhibiting two peaks due to different structural arrangements. This is the area in which the main differences between the OMMT's are identified and, hence, the powder OMMT and the dispersed OMMT of this study are distinctively different, even though similar organic salts were used for the separation of the platelets.

- Between 550 and $800{ }^{\circ} \mathrm{C}$, the mass loss is associated with the loss of structural water from the MMT, known as dihydroxylation. Again, this is the area in which mass changes are expected and observed for the inorganic MMT.

The first observation derived from Figure 6 is that the organomodification has taken place for both $\mathrm{nC} 2$ and $\mathrm{nC} 4$, which became hydrophobic. Because of this, the amount of adsorbed interlayer water is limited and; therefore, the related mass loss is limited too, as can be seen for the temperatures below $200{ }^{\circ} \mathrm{C}[47]$. 


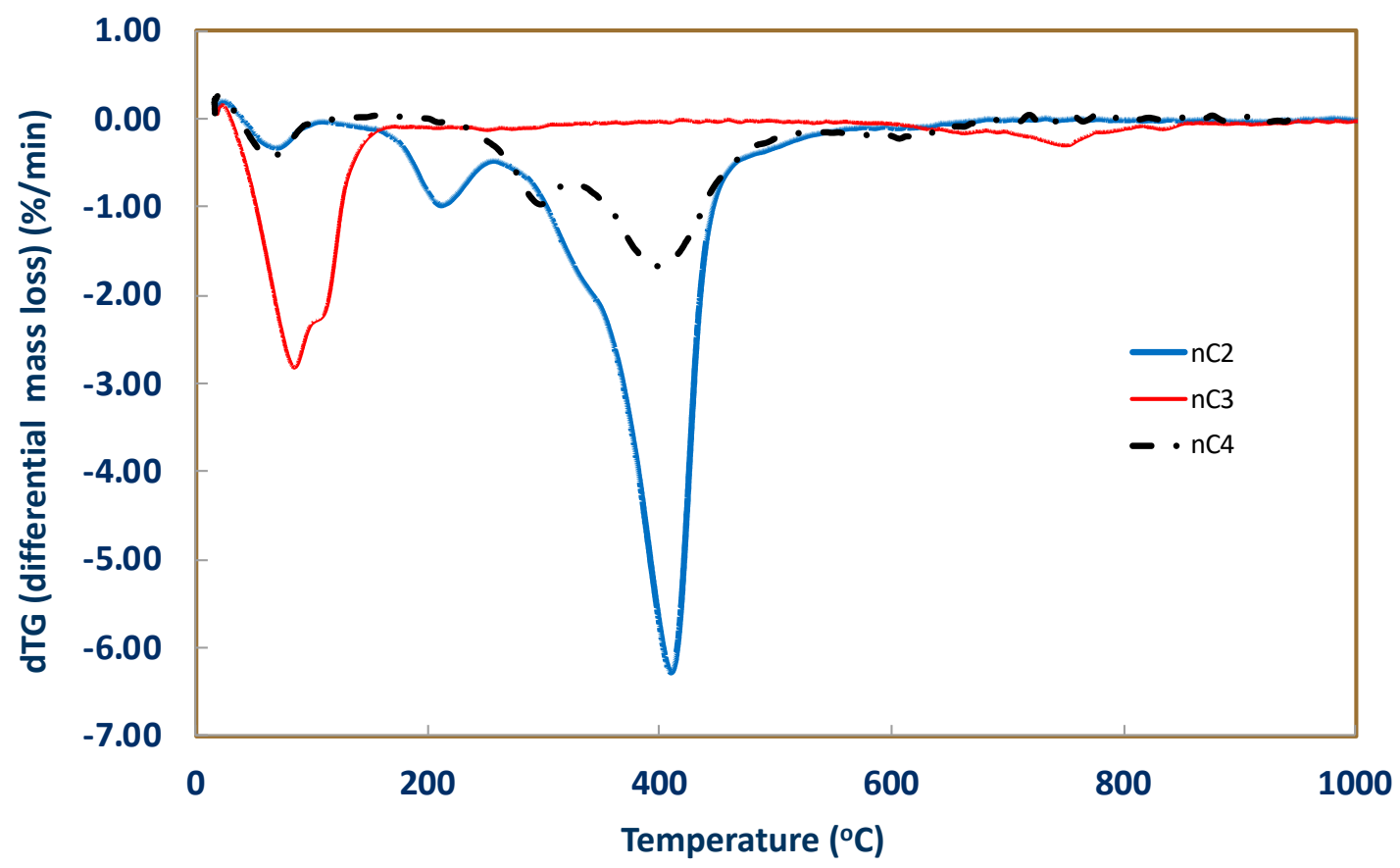

Figure 6. Comparison of Differential mass loss (dTG) of the organomodified montmorillonite (MMT) dispersion (nC2), inorganic MMT dispersion (nC3) [19], and organomodified MMT powder (nC4).

In greater detail, as far as $\mathrm{nC} 4$ was concerned, the TG analysis showed four endothermic peaks (Figure 6 and Table 4):

- In the temperature range of $30-130{ }^{\circ} \mathrm{C}$, with a distinct peak at $67^{\circ} \mathrm{C}$, attributed to the loss of surface and interlayer water.

- In the temperature range of $200-330{ }^{\circ} \mathrm{C}$, with a distinct peak at $295{ }^{\circ} \mathrm{C}$, the decomposition of modifier bound to neighboring molecules took place.

- In the temperature range of $330-530{ }^{\circ} \mathrm{C}$, with a distinct peak at $396^{\circ} \mathrm{C}$, the deconstruction of the modifier bound to the bentonite was completed.

- In the temperature range of $570-700{ }^{\circ} \mathrm{C}$, with a distinct peak at $600{ }^{\circ} \mathrm{C}$, the remaining OMMT was decomposed.

Table 4. Mass loss (\%) of nC4.

\begin{tabular}{cccccc}
\hline & $\mathbf{0 - 1 0 0}{ }^{\circ} \mathrm{C}$ & $\mathbf{1 0 0 - 2 5 0}{ }^{\circ} \mathrm{C}$ & $\mathbf{2 5 0 - 4 0 0}{ }^{\circ} \mathrm{C}$ & $\mathbf{4 0 0 - 5 0 0}{ }^{\circ} \mathrm{C}$ & $\mathbf{5 0 0 - 7 0 0}{ }^{\circ} \mathrm{C}$ \\
\hline $\mathbf{n C 4}$ & 1.33 & 0.31 & 13.63 & 8.00 & 2.86 \\
\hline \multicolumn{5}{c}{ Respectively, analyses for nC2 and nC3 can be found in literature [19]. }
\end{tabular}

\subsection{Characterization of Fiber-Cement Nanohybrids}

\subsubsection{Flexural Strength}

The standard deviation was computed for all specimens and is presented in Figure 7. For the reference paste, F.PC6LS40PVA3SP2, and for the $\mathrm{nC} 2$ modified pastes, it ranged from 1 to 1.4. The addition of $\mathrm{nC} 3$ reduced the variation between 1.0 to $1.2 \mathrm{MPa}$, whereas the standard deviation of $\mathrm{nC} 4$ was approximately equal to $1.1 \mathrm{MPa}$. Hence, as in the case of nMt modified pastes without PVA [32], the standard deviation was improved with $\mathrm{nC} 3$. 


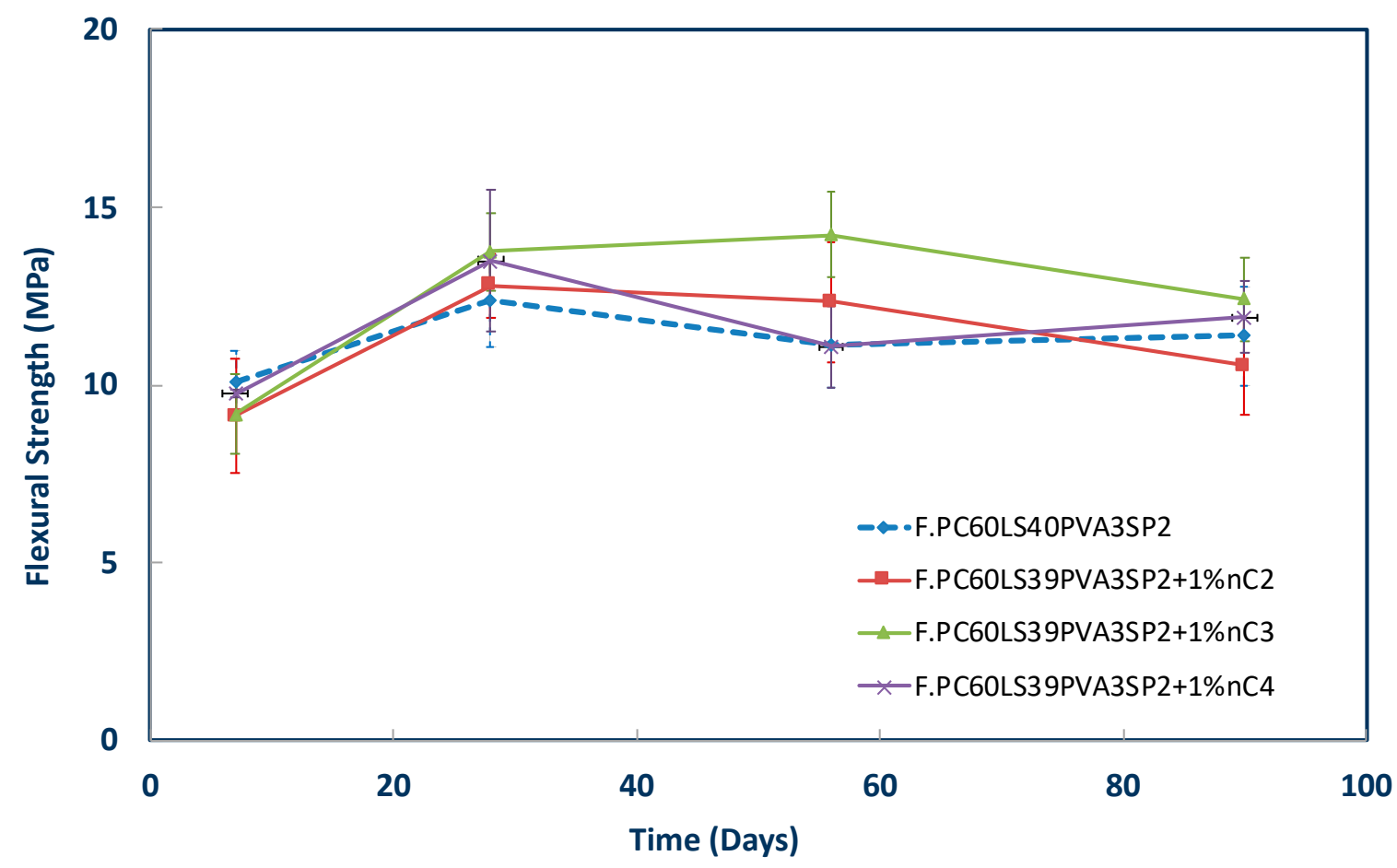

Figure 7. Flexural strength of $1 \% \mathrm{nC} 2, \mathrm{nC} 3$ [28], and nC4 fiber-cement nanohybrids based on F.PC60LS40PVA3SP2.

As shown in Figure 7, given more curing time, the nMt modified pastes outperformed the reference paste, in contrast to [21] who suggested that the nMt particles (just like nanosilica particles) are more effective in the first seven days and their effectiveness reduces at middle ages (28 and 90 days). nC3 showed the highest flexural strength of all three. In fact, at day 28 the nC3 reinforced nanohybrids showed a $7.2 \%$ increase compared to the reference paste, at day 56 a $28 \%$ increase, and at day 90 a $9 \%$ increase in flexural strength compared to the reference formulation. nC2 showed a lower strength at day 56, which could be attributed to bad compaction. If this was the case, then all three types of nMt would not manage to maintain the strength gain after day 56, showing a relative reduction in flexural strength at day 90. It is of particular interest to note that the powder nMt did not offer any major strength improvements, neither did nC2. It should also be noted that PVA fibers are highly hydrophobic; therefore, the hydrophobic nature of $\mathrm{nC} 2$ and $\mathrm{nC} 4$ was possibly responsible for an inferior combination compared to nC3. For this it is postulated that nMt performs best when dispersed in water before being added to any cementitious formulation.

It is possible that with longer mixing time and less amount of fibers, the nMt modified specimens can be better compacted and, consequently, deliver even higher strengths.

Potential re-agglomeration of nanoparticles when added to cementitious matrices is expected to influence rheological properties of pastes, pore structure, and density, and induce weak zones in compression. It has been postulated in previous studies that the use of a sonicator or any other advanced technique, such as generation of nanofluidic droplets, could help (i) eliminate discrepancies (mixing limitations), and (ii) minimize possible agglomeration of the nMt particles in the pastes produced [31]. In the present study the first step for better mixing, compaction, and avoidance of re-agglomeration of nanoparticles or clustering of fibers was the addition of $2 \%$ superplasticizers, magnetic stirring of the $\mathrm{nMt}$ dispersion, and mechanical mixing of the fiber-cement nanohybrids. Results, show; however, that there is room for improvement in the techniques employed, particularly for applications that necessitate the use of fibers. In addition to this, recently a number of papers have been presented on digital or droplet based microfluidics systems, which are particularly important for biological applications [48], or for the generation and manipulation of discrete droplets inside 
micro-devices [49]. Therefore, although this technology is necessary for drug delivery, synthesis of biomolecules and other biological, medical, and pharmaceutical applications, it would be interesting to test it in cementitious nanohybrids in order to compare it with more traditional methods of nanoparticle addition in cementitious matrices, in future research. The effect on the fresh properties of pastes with the different nanoparticle addition methods would also be interesting to investigate and report upon.

\subsubsection{Thermal Gravimetric Analyses}

For these series of fiber cement pastes, the $1 \% \mathrm{nC} 2, \mathrm{nC} 3$ and $\mathrm{nC} 4$ content were analyzed. It should be noted that, again, the amount of decomposing modifier and/or clay were deducted from the mass loss occurring at $400-500{ }^{\circ} \mathrm{C}$ temperature range and at $600-800{ }^{\circ} \mathrm{C}$ temperature range, respectively, as discussed in literature $[19,46]$. No consumption of $\mathrm{Ca}(\mathrm{OH})_{2}$ seemed to have taken place (Figure $8 \mathrm{~A}$ ). In addition, it can be claimed that no carbonation occurred, since the lines representing the nanomodified pastes are below that of the reference paste (Figure 8B).
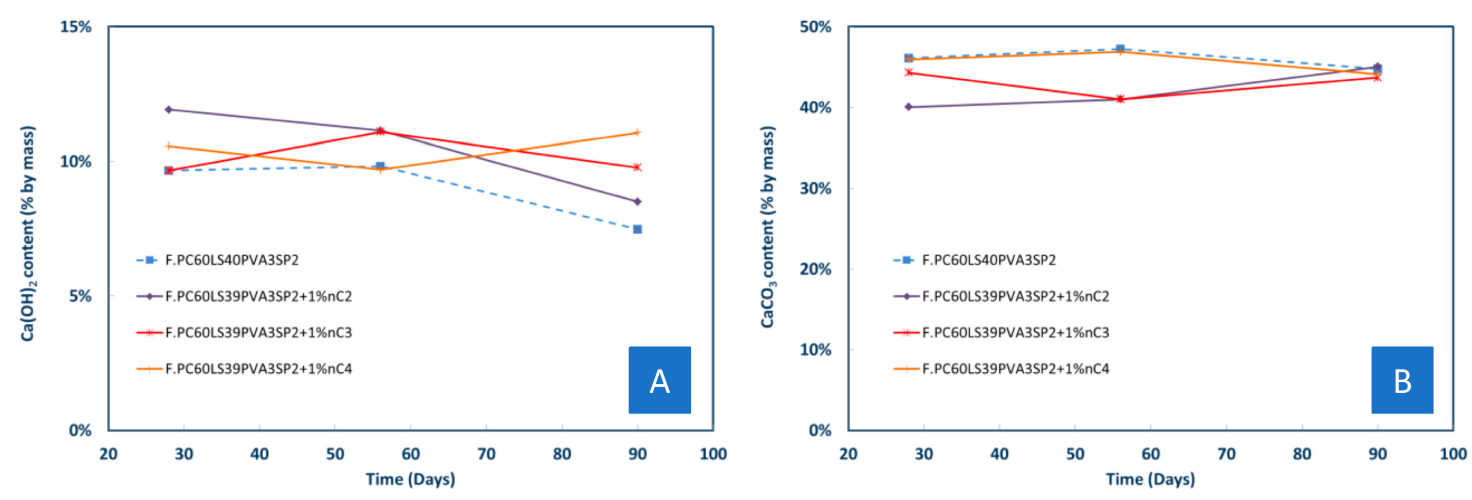

Figure 8. Effect of nMT type on $(\mathbf{A}) \mathrm{Ca}(\mathrm{OH})_{2}$ and (B) $\mathrm{CaCO}_{3}$ content of fiber-cement nanohybrids based on F.PC60LS40PVA3SP2.

Further analysis was carried out with respect to the temperature range within which ettringite and C-S-H decompose. As shown in Figure 9, nC2 seemed to have generated greater quantities of ettringite $\left(100-125^{\circ} \mathrm{C}\right)$ and $\mathrm{C}-\mathrm{S}-\mathrm{H}$, with $\mathrm{nC} 3$ following, given the time. In full agreement with the flexural strength results, $\mathrm{nC} 3$ showed the greatest production of ettringite and $\mathrm{C}-\mathrm{S}-\mathrm{H}$ at day 90 . Lastly, nC4 did not show much difference compared to the reference paste, either in terms of TGA or in terms of flexural performance. 

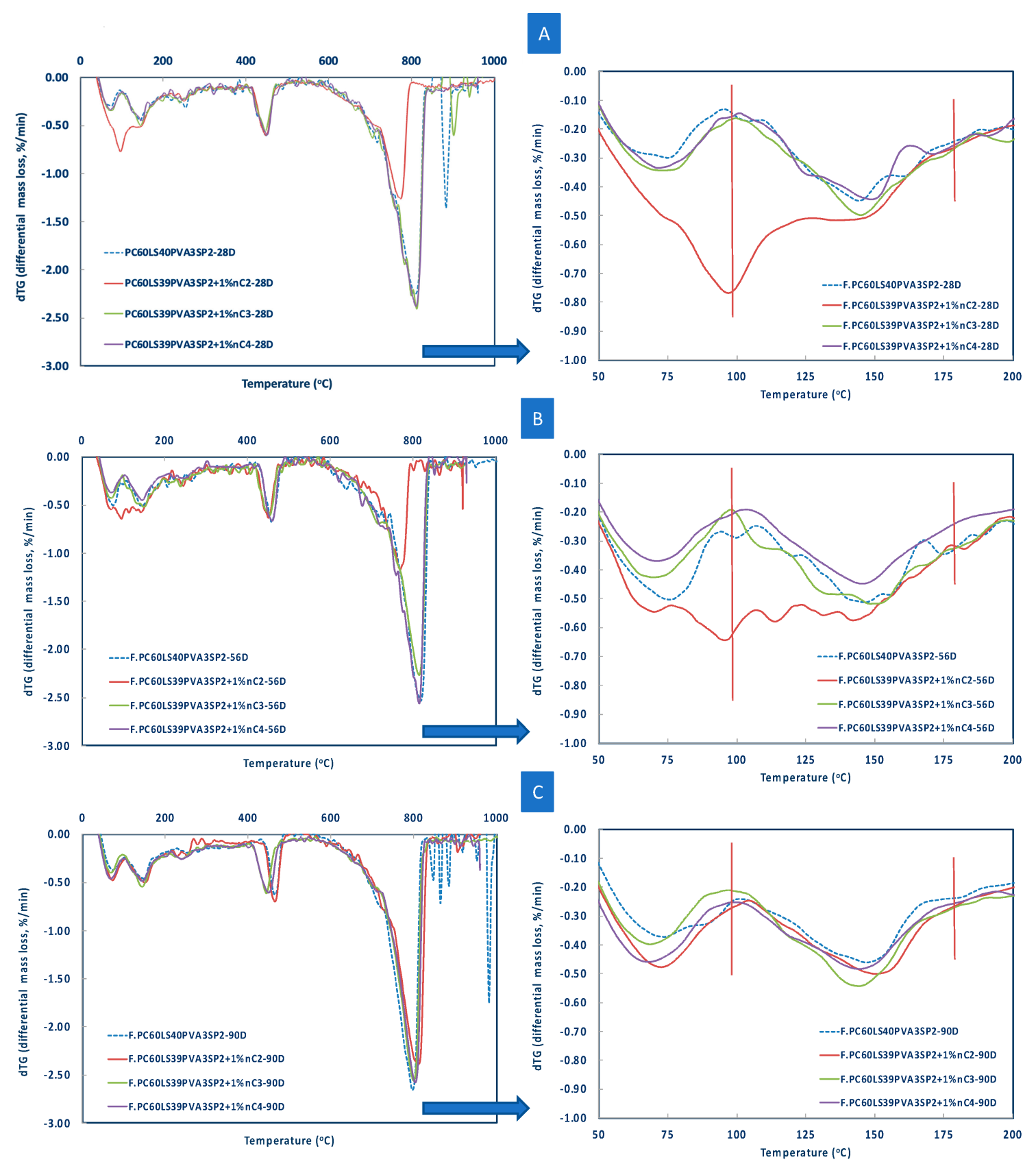

Figure 9. Differential mass loss of fiber-cement nanohybrids based on F.PC60LS40PVA3SP2 between 100-200 ${ }^{\circ} \mathrm{C}$ at (A) day 28, (B) day 56, and (C) day 90.

\subsubsection{Crystallographic Analyses (XRD)}

The fact that no significant $\mathrm{Ca}(\mathrm{OH})_{2}$ consumption or carbonation took place was also confirmed by the XRD analyses executed indicatively on F.PC60LS40PVA3SP2 and the 1\% nC3 and $\mathrm{nC} 4$ addition at day 28, as shown in Figure 10. 


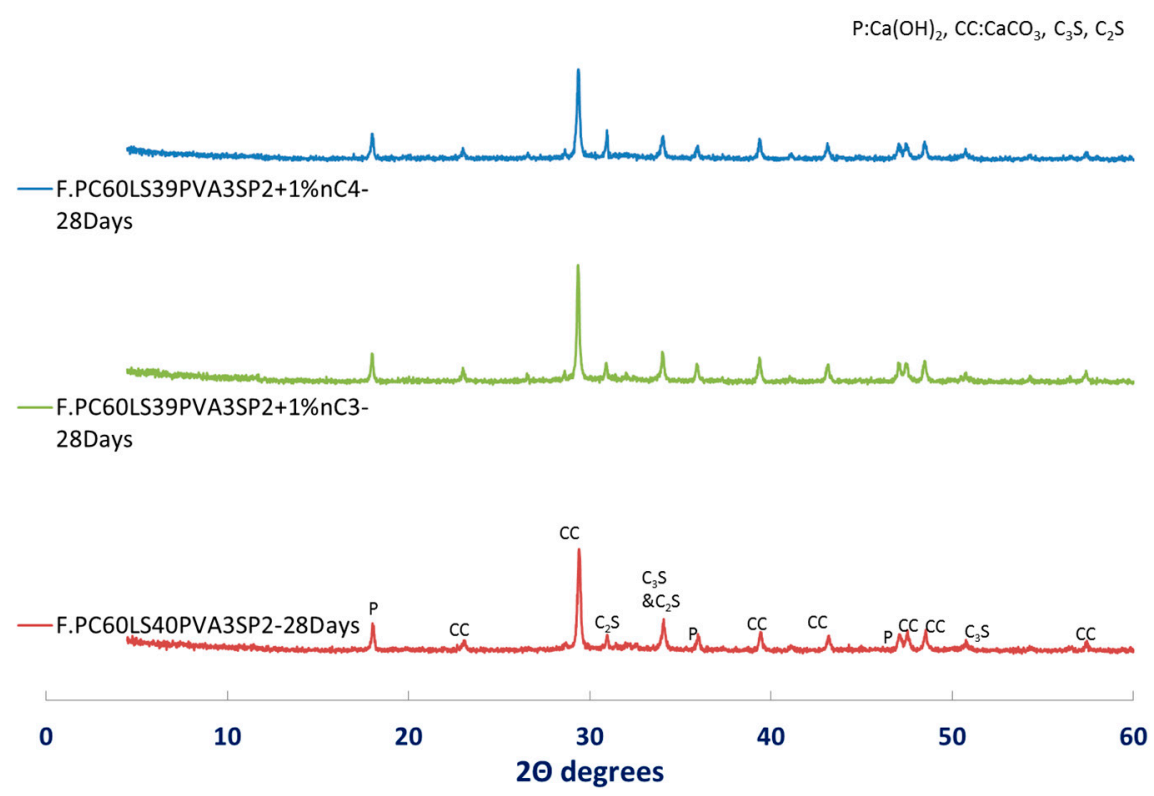

Figure 10. XRD pattern of fiber-cement nanohybrids based on F.PC60LS40PVA3SP2 at day 28—effect of nMt type.

Having completed the flexural strength tests, the thermal gravimetric and the crystallographic analyses, it can be observed that the $\mathrm{nC} 2$ and $\mathrm{nC} 3$ modified fiber pastes showed improved flexural performance; however, the difficulty of compaction of such pastes incorporating fibers and nMt can lead to increased clustering of the various particles, leading to greater strength variations. Improvements could firstly involve the $\mathrm{nMt}$ production method. Maybe less organic modifier should have been used for nC2 [19]. Carbon seemed to be applying a critical barrier by covering the platelets, possibly not allowing them to react as intended as stated in literature [19]. It is also possible that the excess of the organomodifier had a physical effect, as well, making the platelets re-agglomerate rather than keeping them apart. In future research, advanced ball milling techniques for the production of OMMT with anionic or non-ionic surfactants without any added water can be employed for better intercalation and thermal properties [50].

Moreover, PVA fiber content could be reduced to $1 \%$. This would also make the nMt's in the samples be more homogeneously dispersed. Future research could include studies of fresh properties, including consistency tests in order to optimize the formulation design with respect to the fiber and superplasticizer content.

Possibly, both OMMT's (nC2 and $\mathrm{nC} 4)$ were primarily intercalated rather than exfoliated. If they were fully exfoliated they may have performed better, as the charge would have made the platelets repulse each other and they; therefore, would have been individually available for reactions. In other words, their significant surface area would have been better utilized. Particularly in the case of the powder $\mathrm{nMt}, \mathrm{nC} 4$, the platelets may have re-agglomerated within the hydrating paste. All results; therefore, suggest that nMt's should be better employed in aqueous dispersions if to be used in cementitious formulations. Adding to this, according to literature, montmorillonite K-10, on which $\mathrm{nC} 4$ is based, is produced via calcination [51], which is a $\mathrm{CO}_{2}$ intensive process. The above results indicate that there should be a shift towards non-thermally treated montmorillonites, as the calcined ones do not offer such enhancement that can counteract the damage to the environment.

The inorganic $\mathrm{nC} 3$ dispersion was proven to contribute to flexural strength enhancement through the pozzolanic reaction. However, further research is required with respect to impermeability characteristics of pastes modified with $\mathrm{nC} 3$, as a tendency to adsorb water was observed in pastes containing only $P C$ and $L S$. Pastes containing $P C, L S$, and FA, showed enhanced performance by 
adsorbing less water than the reference paste, but further research is required with respect to later age performance.

3.2.4. Relative Density, Water Impermeability Analyses, and Mercury Intrusion Porosimetry (MIP)

Late age, (after month three) relative density measurements were taken of the three fiber-cement nanohybrids. All measurements showed a very low standard deviation and similar values of relative density (Figure 11).

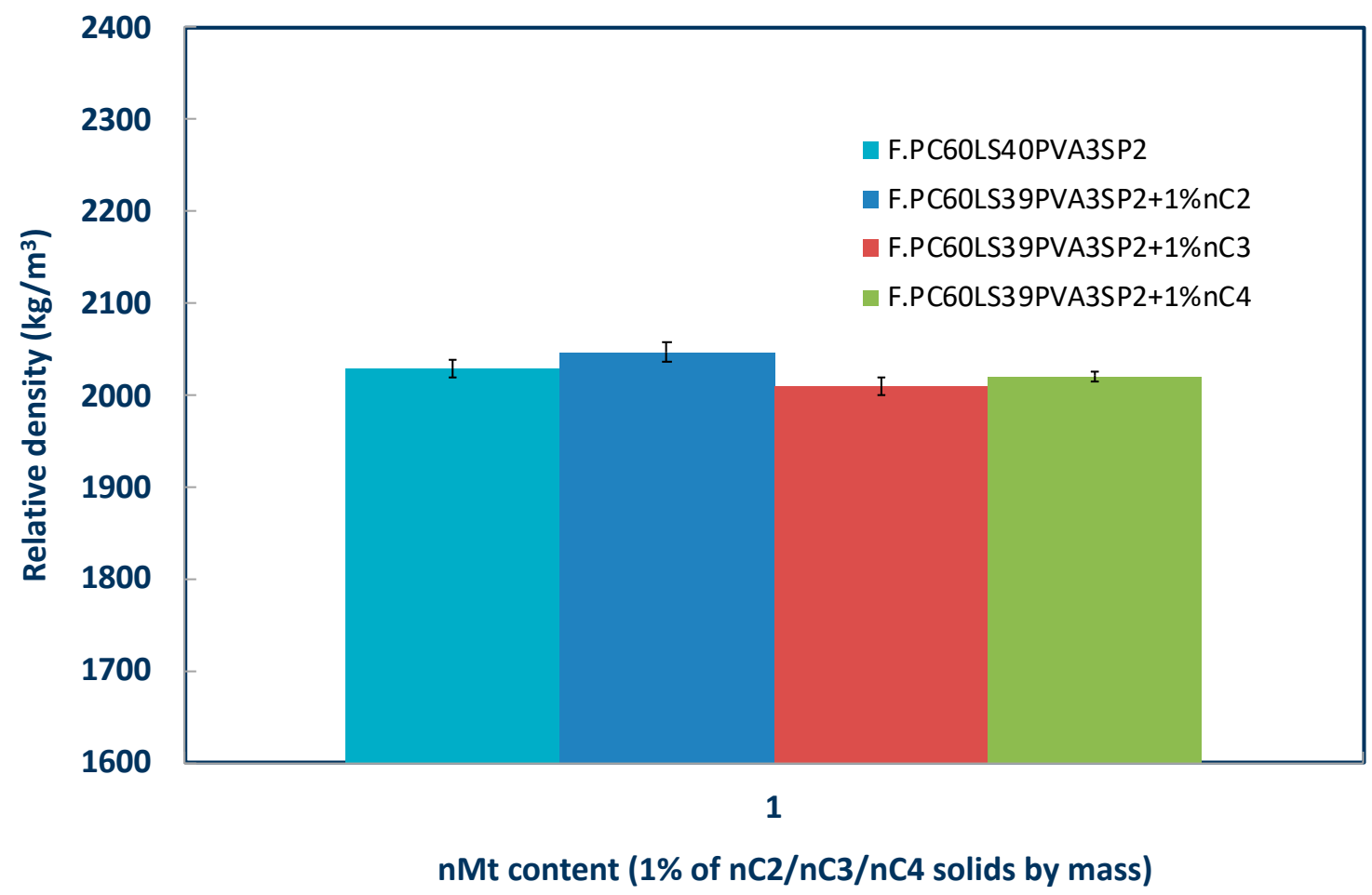

Figure 11. Effect of nMt type (at 1\% dosage) on long term relative density of fiber-cement nanohybrids based on F.PC60LS40PVA3SP2.

\subsubsection{Water Impermeability Tests}

Water impermeability tests were carried out in accordance with BS EN 492:2012, with modifications accounting for the much smaller specimens used in this research. Nanohybrids modified by hydrophilic (nC3) or hydrophobic (nC2 and $\mathrm{nC} 4)$ types of $\mathrm{nMt}$ may present water permeability issues at later ages, as shown in Figure 12. In greater detail, of the organomodified nMt's, nC2 showed the best performance at later ages, whereas the industrially-produced $\mathrm{nC} 4$ seemed to perform better than the reference paste only at early ages. Comparing the OMMT dispersion (nC2) and the inorganic $\mathrm{nMt}$ dispersion (nC3), $\mathrm{nC} 3$ seems to be promising, but if water impermeability is a prerequisite for certain applications, then all $\mathrm{nMt}$ reinforced matrices should always be checked at later ages. 


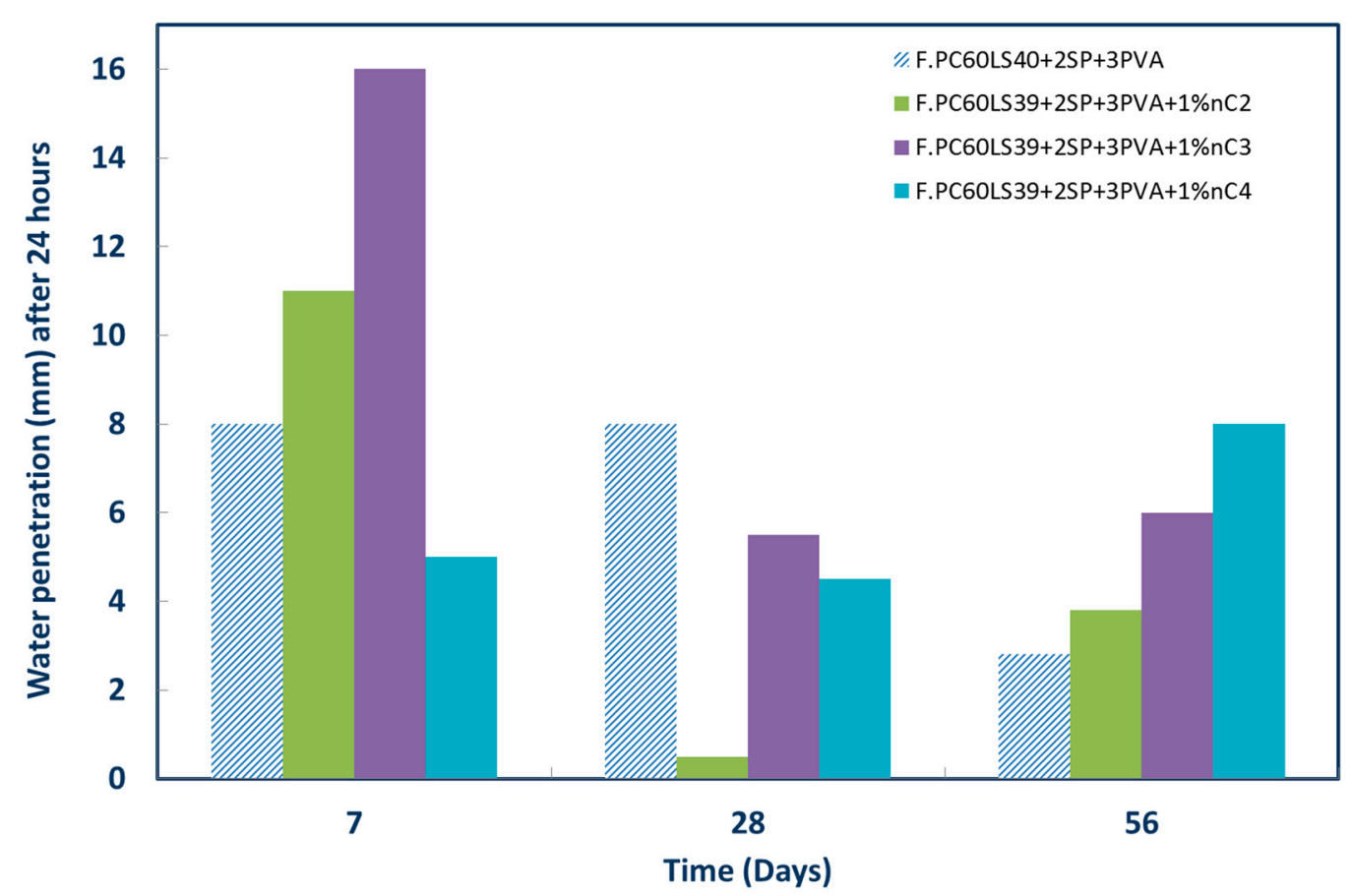

Figure 12. Effect of nMt type (at 1\% dosage) on the impermeability of fiber-cement nanohybrids based on F.PC60LS40PVA3SP2.

\subsubsection{Mercury Intrusion Porosimetry (MIP)}

For the fiber-cement pastes based on F.PC60LS40PVA3SP2, only two formulations were tested indicatively via MIP. These were the reference paste itself (F.PC60LS40PVA3SP2) and the 1\% nC3 modified paste (F.PC60LS39PVA3SP2 $+1 \%$ nC3), which seemed to be a successful formulation according to the analyses presented above. Both samples were tested at day 28 (Table 5).

Table 5. Mercury intrusion data summary comparison of F.PC60LS40PVA3SP2 and F.PC60LS39PVA3SP2+1\%nC3.

\begin{tabular}{|c|c|c|c|c|c|c|c|c|}
\hline \multicolumn{9}{|c|}{ Mercury Intrusion Data Summary at 28 Days } \\
\hline Paste & $\begin{array}{c}\text { A }_{\text {pore-Total }} \\
\left(\mathrm{m}^{2} / \mathrm{g}\right)\end{array}$ & $\begin{array}{c}F_{\text {pore Volume-Med }} \\
(\mathrm{nm})\end{array}$ & $\begin{array}{c}F_{\text {pore Area-Med }} \\
(\mathrm{nm})\end{array}$ & $\begin{array}{c}R_{\text {bulk }} \\
(\mathrm{g} / \mathrm{mL})\end{array}$ & $\mathrm{F}_{\text {pore-Average }}(\mathrm{nm})$ & $\underset{(\mathrm{g} / \mathrm{mL})}{\mathrm{R}_{\text {apparent }}}$ & $\begin{array}{c}\text { Porosity } \\
(\%)\end{array}$ & $\begin{array}{c}\mathrm{V}_{\text {stem-Used }} \\
(\%)\end{array}$ \\
\hline F.PC60LS40PVA3SP2 & 45.8 & 76.8 & 5.1 & 1.6 & 18.9 & 2.4 & 34.1 & 50.0 \\
\hline
\end{tabular}

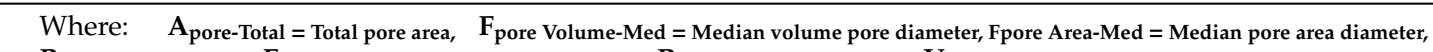

$\mathbf{R}_{\text {bulk }}=$ Bulk density, $\mathbf{F}_{\text {pore-Average }=\text { Average Pore diameter },} \mathbf{R}_{\text {appar }}=$ Apparnt density, $\mathbf{V}_{\text {stem-Used }=\text { Stem Volume Used }}$

It can be seen that the total pore area, median volume pore diameter, and porosity were increased. This can be attributed to the presence of the fibers and mixing effects. The apparent and bulk density; however, showed small fluctuations.

Although it is acknowledged that the MIP results are not conclusive, the two formulations were tested indicatively to assist the discussion on the impermeability tests, reinforce the mechanical strength results, and provide suggestions for future research. The increase in pore diameter and porosity can be attributed to the presence of fibers, because separate studies on the PC60LS40 matrix, without the presence of fibers and superplasticizers but with varying amounts of $\mathrm{nC} 3$, showed that $\mathrm{nC} 3$, possibly because of the better exfoliation and dispersion of the nMt platelets in the bulk of the aqueous dispersion, showed decreased porosity compared with the reference paste [29], in support of the argument that inorganic nMt can act as nucleation point and nanofiller improving the particle packing.

Further research on the pore structure of $\mathrm{nMt}$ and fiber-reinforced nanohybrids could involve the use of other techniques, such as X-ray tomography (CT) scan, to determine the absolute values 
of porosity, pore area, and other parameters. However, it should be noted that, since nC3 showed acceptable density, water permeability, and pore structure performance (along with better flexural strength and thermal properties), further research into applications that necessitate these characteristics, such as pervious concrete pavements [52], could yield interesting results.

\section{Conclusions}

In this paper, a successful application of the nMt's was achieved by incorporating them in fiber-cement nanohybrids. Until present, this is the first study that:

1. Extends from the characterization of nanoparticles to the characterization of fiber-cement nanohybrids.

2. Is applied to ternary fiber-cement nanohybrids directly.

3. Compares the effect of hydrophilic or hydrophobic nMt.

4. Compares the effect of dispersed hydrophobic nMt or powder hydrophobic nMt.

5. Correlates the flexural performance beyond day 28 , an indeed more critical period, with the TGA results relating to the consumption of $\mathrm{Ca}(\mathrm{OH})_{2}$ towards the production of $\mathrm{C}-\mathrm{S}-\mathrm{H}$.

In brief, major conclusions include the following:

1. The organomodified aqueous dispersion of $\mathrm{nMt}, \mathrm{nC2}$, can be better developed as a material by studying various combinations of production methods, such as ball milling, in order for the product to necessitate lower amounts of modifier (i.e., less carbon addition).

2. The inorganic aqueous dispersion of $\mathrm{nMt}, \mathrm{nC} 3$, offered strength, thermal, and microstructural improvements.

3. The industrial powder $\mathrm{nMt}$, nC4, did not offer any strength, chemical, or microstructural enhancements.

4. Different methods for nMt dispersion in cementitious matrices can be assessed in future research to achieve homogeneous mixing and easy compaction, which should reflect in the pore structure and fresh properties of pastes.

Author Contributions: Conceptualization, S.P. and K.P.; methodology, S.P.; software, S.P.; analysis, S.P.; investigation, S.P.; writing—original draft preparation, S.P.; writing—review and editing, S.P.; funding acquisition, K.P.

Funding: This research was funded by the European Commission (FIBCEM project, grant No. 262954).

Acknowledgments: All partners are thanked for their input and for the supply of materials. The authors would also like to thank the Department of Chemical Engineering at the University of Bath for the use of the TG analyzer.

Conflicts of Interest: The authors declare no conflicts of interest. The funders had no role in the design of the study; in the collection, analyses or interpretation of data; in the writing of the manuscript or in the decision to publish the results.

\section{References}

1. Papatzani, S. Effect of nanosilica and montmorillonite nanoclay particles on cement hydration and microstructure. Mater. Sci. Technol. 2016, 32, 138-153. [CrossRef]

2. Sapalidis, A.A.; Katsaros, F.K.; Kanellopoulos, N.K. PVA/Montmorillonite Nanocomposites: Development and Properties. In Nanocomposites Polymers with Analytical Methods; Cuppoletti, J., Ed.; InTech: Horwich, UK, 2011.

3. European Commission. Commission Recommendation of 18 October 2011 on the Definition of Nanomaterial; 2011/696/EU 2011; OJEC: Aberdeen, UK, 2011.

4. Agubra, A.V.; Owuor, S.P.; Hosur, V.M. Influence of Nanoclay Dispersion Methods on the Mechanical Behavior of E-Glass/Epoxy Nanocomposites. Nanomaterials 2013, 3. [CrossRef]

5. Aktas, L.; Altan, M.C. Effect of nanoclay content on properties of glass-waterborne epoxy laminates at low clay loading. Mater. Sci. Technol. 2010, 26, 626-629. [CrossRef] 
6. Hetzer, M.; Zhou, H.X.; Poloso, T.; De Kee, D. Influence of compatibiliser blends on mechanical and thermal properties of polymer-clay nanocomposites. Mater. Sci. Technol. 2011, 27, 53-59. [CrossRef]

7. Meng, X.Y.; Wang, Z.; Tang, T. Controlling dispersed state and exfoliation process of clay in polymer matrix. Mater. Sci. Technol. 2006, 22, 780-786. [CrossRef]

8. Utracki, L.A. Clay-Containing Polymeric Nanocomposites-Volume 1. Shawbury, Shrewsbury, Shropshire, SY4 4NR; Rapra Technology Limited: Telford, UK, 2004.

9. Xi, Y. Synthesis, Characterisation and Application of Organoclays. Ph.D. Thesis, Queensland University of Technology, Brisbane City, Australia, 2006.

10. Carrizosa, M.J.; Hermosin, M.C.; Koskinen, W.C.; Cornejo, J. Use of Organosmectites to Reduce Leaching Losses of Acidic Herbicides. Soil Sci. Soc. Am. J. 2003, 67, 511-517. [CrossRef]

11. Annamalai, P.K.; Martin, D.J. Can clay nanoparticles accelerate environmental biodegradation of polyolefins? Mater. Sci. Technol. 2014, 30, 593-602. [CrossRef]

12. Viseras, C.; Aguzzi, C.; Cerezo, P.; Bedmar, M.C. Biopolymer-clay nanocomposites for controlled drug delivery. Mater. Sci. Technol. 2008, 24, 1020-1026. [CrossRef]

13. Papatzani, S.; Paine, K.; Calabria-Holley, J. A comprehensive review of the models on the nanostructure of calcium silicate hydrates. Constr. Build. Mater. 2015, 74, 219-234. [CrossRef]

14. Chang, T.P.; Shih, J.Y.; Yang, K.M.; Hsiao, T.C. Material properties of Portland cement paste with nano-montmorillonite. J. Mater. Sci. 2007, 42, 7478-7487. [CrossRef]

15. Morsy, M.S.; Alsayed, S.H.; Aqel, M. Hybrid effect of carbon nanotube and nano-clay on physico-mechanical properties of cement mortar. Constr. Build. Mater. 2011, 25, 145-149. [CrossRef]

16. Kuo, W.-Y.; Huang, J.-S.; Lin, C.-H. Effects of organo-modified montmorillonite on strengths and permeability of cement mortars. Cem. Concr. Res. 2006, 36, 886-895. [CrossRef]

17. Fernandez, R.; Martirena, F.; Scrivener, K.L. The origin of the pozzolanic activity of calcined clay minerals: A comparison between kaolinite, illite and montmorillonite. Cem. Concr. Res. 2011, 41, 113-122. [CrossRef]

18. BSI. BS EN 197-1:2011: Cement. Part 1: Composition, Specifications and Conformity Criteria for Common Cements; BSI: London, UK, 2011.

19. Papatzani, S.; Paine, K. Inorganic and organomodified nano-montmorillonite dispersions for use as supplementary cementitious materials-A novel theory based on nanostructural studies. Nanocomposites 2017, 3, 2-19. [CrossRef]

20. He, X.; Shi, X. Chloride permeability and microstructure of Portland cement mortars incorporating nanomaterials. Transp. Res. Rec. J. Transp. Res. Board 2008, 2070, 13-21. [CrossRef]

21. Hosseini, P.; Hosseinpourpia, R.; Pajum, A.; Khodavirdi, M.M.; Izadi, H.; Vaezi, A. Effect of nano-particles and aminosilane interaction on the performances of cement-based composites: An experimental study. Constr. Build. Mater. 2014, 66, 113-124. [CrossRef]

22. Li, Z.; Gong, J.; Du, S.; Wu, J.; Li, J.; Hoffman, D.; Shi, X. Nano-montmorillonite modified foamed paste with a high volume fly ash binder. RSC Adv. 2017, 7, 9803-9812. [CrossRef]

23. Fan, Y.; Zhang, S.; Wang, Q.; Shah, S.P. Effects of nano-kaolinite clay on the freeze-thaw resistance of concrete. Cem. Concr. Compos. 2015, 62,1-12. [CrossRef]

24. Hakamy, A.; Shaikh, F.U.A.; Low, I.M. Microstructures and mechanical properties of hemp fabric reinforced organoclay-cement nanocomposites. Constr. Build. Mater. 2013, 49, 298-307. [CrossRef]

25. Morsy, M.S.; Alsayed, S.H.; Aqel, M. Effect of nano-clay on mechanical properties and microstructure of ordinary Portland cement mortar. Int. J. Civ. Environ. Eng. IJCEE-IJENS 2009, 10, $23-27$.

26. Al-Salami, A.E.; Morsy, M.S.; Taha, S.; Shoukry, H. Physico-mechanical characteristics of blended white cement pastes containing thermally activated ultrafine nano clays. Constr. Build. Mater. 2013, 47, 138-145. [CrossRef]

27. Čèsnienè, J.; Baltušnikas, A.; Lukošiūtè, I.; Brinkienė, K.; Kalpokaitė-Dičkuvienė, R. Influence of organoclay structural characteristics on properties and hydration of cement pastes. Constr. Build. Mater. 2018, 166, 59-71. [CrossRef]

28. Papatzani, S.; Paine, K. Dispersed Inorganic or Organomodified Montmorillonite Clay Nanoparticles for Blended Portland Cement Pastes: Effects on Microstructure and Strength. In Nanotechnology in Construction; Sobolev, K., Shah, S.P., Eds.; Springer International Publishing: Cham, Switzerland, 2015; pp. 131-139. 
29. Papatzani, S.; Grammatikos, S.; Adl-Zarrabi, B.; Paine, K. Pore-structure and microstructural investigation of organomodified/Inorganic nano-montmorillonite cementitious nanocomposites. Am. Inst. Phys. 2018, 1957, 030004. [CrossRef]

30. Papatzani, S.; Paine, K. Optimization of Low-Carbon Footprint Quaternary and Quinary (37\% Fly Ash) Cementitious Nanocomposites with Polycarboxylate or Aqueous Nanosilica Particles. Adv. Mater. Sci. Eng. 2019, 2019, 26. [CrossRef]

31. Papatzani, S.; Paine, K. Polycarboxylate/nanosilica-modified quaternary cement formulationsEnhancements and limitations. Adv. Cem. Res. 2018, 30, 256-269. [CrossRef]

32. Papatzani, S.; Paine, K. Lowering cement clinker: A thorough, performance based study on the use of nanoparticles of $\mathrm{SiO}_{2}$ or montmorillonite in Portland limestone nanocomposites. Eur. Phys. J. Plus 2018, 133, 430. [CrossRef]

33. Calabria-Holley, J.; Papatzani, S.; Naden, B.; Mitchels, J.; Paine, K. Tailored montmorillonite nanoparticles and their behaviour in the alkaline cement environment. Appl. Clay Sci. 2017, 143, 67-75. [CrossRef]

34. Stefanidou, M.; Papayianni, I. Influence of nano- $\mathrm{SiO}_{2}$ on the Portland cement pastes. Compos. Part B Eng. 2012, 43, 2706-2710. [CrossRef]

35. Naeem, F.; Lee, H.K.; Kim, H.K.; Nam, I.W. Flexural stress and crack sensing capabilities of MWNT/cement composites. Compos. Struct. 2017, 175, 86-100. [CrossRef]

36. Mohamed, A.M. Influence of nano materials on flexural behavior and compressive strength of concrete. HBRC J. 2016, 12, 212-225. [CrossRef]

37. Yu, P.; Wang, Z.; Lai, P.; Zhang, P.; Wang, J. Evaluation of mechanic damping properties of montmorillonite/organo-modified montmorillonite-reinforced cement paste. Constr. Build. Mater. 2019, 203, 356-365. [CrossRef]

38. Horikoshi, T.; Ogawa, A.; Saito, T.; Hoshiro, H. Properties of Polyvinylalcohol fibre as reinforcing materials for cementitious composites. Int. Work HPFRCC Struct. Appl. 2005, 2, 1-8.

39. Goodhew, P.J. Electron Microscopy and Analysis; Goodhew, P.J., Ed.; Wykeham Publications: London, UK; Springer: New York, NY, USA, 1975.

40. Calabria-Holley, J.; Papatzani, S. Effects of nanosilica on the calcium silicate hydrates in Portland cement-fly ash systems. Adv. Cem. Res. 2014, 26,1-14. [CrossRef]

41. Zhang, J.; Scherer, G.W. Comparison of methods for arresting hydration of cement. Cem. Concr. Res. 2011, 41, 1024-1036. [CrossRef]

42. Struble, L.; Livesey, P.; Del Strother, P.; Bye, G. Portland Cement; ICE Publishing: London, UK, 2011.

43. Sinha Ray, S.; Okamoto, M. Polymer/layered silicate nanocomposites: A review from preparation to processing. Prog. Polym. Sci. 2003, 28, 1539-1641. [CrossRef]

44. Manias, E.; Touny, A.; Wu, L.; Strawhecker, K.; Lu, B.; Chung, T.C. Polypropylene/Montmorillonite Nanocomposites. Review of the Synthetic Routes and Materials Properties. Chem. Mater. 2001, 13, 3516-3523. [CrossRef]

45. Bekri-Abbes, I.; Srasra, E. Effect of mechanochemical treatment on structure and electrical properties of montmorillonite. J. Alloys Compd. 2016, 671, 34-42. [CrossRef]

46. Papatzani, S.; Badogiannis, E.G.; Paine, K. The pozzolanic properties of inorganic and organomodified nano-montmorillonite dispersions. Constr. Build. Mater. 2018, 167, 299-316. [CrossRef]

47. Nie, J.; Ke, Y.; Zheng, H.; Yi, Y.; Qin, Q.; Pan, F.; Dong, P. Preparation and Characterization of Organo Montmorillonite Modified by a Novel Gemini Surfactant. Integr. Ferroelectr. 2012, 137, 67-76. [CrossRef]

48. Bransky, A.; Korin, N.; Khoury, M.; Levenberg, S. A microfluidic droplet generator based on a piezoelectric actuator. Lab Chip 2009, 9, 516-520. [CrossRef]

49. Teh, S.-Y.; Lin, R.; Hung, L.-H.; Lee, A.P. Droplet microfluidics. Lab Chip 2008, 8, 198-220. [CrossRef] [PubMed]

50. Zhuang, G.; Zhang, Z.; Guo, J.; Liao, L.; Zhao, J. Applied Clay Science A new ball milling method to produce organo-montmorillonite from anionic and nonionic surfactants. Appl. Clay Sci. 2015, 104, 18-26. [CrossRef] 
51. Cornélis, A.; Laszlo, P.; Zettler, M.W.; Das, B.; Srinivas, K.V.N.S. Montmorillonite K10. Encycl. Reagents Org. Synth. 2004. [CrossRef]

52. Shakrani, S.A.; Ayob, A.; Rahim, M.A.A. A review of nanoclay applications in the pervious concrete pavement. In AIP Conference Proceedings; AIP Publishing: Melville, NY, USA, 2017; Volume 1885, p. 020049.

(C) 2019 by the authors. Licensee MDPI, Basel, Switzerland. This article is an open access article distributed under the terms and conditions of the Creative Commons Attribution (CC BY) license (http://creativecommons.org/licenses/by/4.0/). 